\author{
$n^{\circ}$ 2014-13 \\ The Impact of Hazardous Industrial \\ Facilities on Housing Prices : \\ A Comparison of Parametric and \\ Semiparametric Hedonic Price Models \\ C. GRISLAIN-LETRÉMY ${ }^{1}$ \\ A. KATOSSKY ${ }^{2}$
}

May, 2014

Les documents de travail ne reflètent pas la position du CREST et n'engagent que leurs auteurs.

Working papers do not reflect the position of CREST but only the views of the authors.

\footnotetext{
1 INSEE - CREST and University Paris Dauphine. Email : celine.grislain.letremy@ensae.fr

2 Email : arthur.katossky@gmail.com
} 


\title{
The Impact of Hazardous Industrial Facilities on Housing Prices: A Comparison of Parametric and Semiparametric Hedonic Price Models*
}

\author{
Céline Grislain-LetrémY ${ }^{\dagger}$ Arthur KatosskY ${ }^{\ddagger}$
}

May 23, 2014

\begin{abstract}
The willingness of households to pay for prevention against industrial risks can be revealed by real estate markets. By using very rich microdata, we study housing prices in the vicinity of hazardous industries near three important French cities. We show that the impact of hazardous plants on the housing values strongly differs among these three areas, even if the areas all surround chemical and petrochemical industries. We compare the results from both standard parametric and more flexible, semiparametric models of hedonic property. We show that the parametric model might structurally lead to important biases in the estimated value of the impact of hazardous plants on housing values and in the variations of this impact with respect to the distance from the plants.
\end{abstract}

Keywords: hedonic analysis, locally weighted regression, urban housing markets, industrial risk.

JEL classification: C21, Q51, R52, R21.

\footnotetext{
${ }^{*}$ The conclusions and analysis set in this paper are those of the authors and do not indicate the views or opinions of their institutions. The authors are grateful to Pierre-Philippe Combes, Éric Dubois, Laurent Gobillon, Nicolas Grislain, Anne Lafferère, Claire Lelarge, David Martimort, Philippe Mongin, Corinne Prost, Sandrine Spaeter, Corentin Trevien and Bertrand Villeneuve for their reading and insightful comments. They also thank Pauline Charnoz, Amélie Mauroux and participants at the 28th annual congress of the European Economic Association, the 12th International Workshop Spatial Econometrics and Statistics, the 2013 INSEE research seminar on "Real estate in France, analyses and prospects," the 2012 European Association of Environmental and Resource Economists', the European Regional Science Association's, and Louis-André Gérard Varet's annual conferences for their comments. The authors are grateful to the French Ministry of Ecology for having funded the data collection when they were working there. Specifically, they thank Vincent Binet, Rémi Borel, Olivier Dupret, François Filior, Martine Giloppe, Jeanne-Marie Gouiffès, and Brigitte Pouget from the Technical Studies Center of Public Works of Normandy and Centre, Nord and Picardy, and South West France for their help with the data collection and standardization. The authors thank Christophe Yon for creating some maps provided in this article. The Finance and Sustainable Development Chair is thanked.

${ }^{\dagger}$ INSEE, CREST and University Paris-Dauphine. Email: celine.grislain.letremy@ensae.fr.

${ }^{\ddagger}$ Email: arthur.katossky@gmail.com. This work was started when both authors were working at the French Ministry of Ecology and then at INSEE.
} 


\section{Introduction}

Real estate markets can demonstrate their households' willingness to pay to reduce their exposure to hazardous industrial facilities. Indeed, hazardous industrial activities generate strong negative externalities: neighboring populations partly bear the cost of a potential industrial accident; and they can also endure day-to-day nuisances associated with the ordinary course of these activities. However, these facilities also generate positive externalities (Greenstone et al., 2010): they provide, directly and indirectly, employment; and through local taxes, they can contribute to the economic development of the municipalities. Measuring the impact of the distance from the hazardous facilities on the housing values reveals to what extent the facilities' activities are perceived as disamenities.

We estimate the impact of the distance from the hazardous facilities on the housing values by using hedonic price models. The first-order derivative of the hedonic price function with respect to the distance from the hazardous plants provides an estimate of the buyers' willingness to pay to live far from these plants. We study housing prices in the vicinity of three important French cities (Bordeaux, Dunkirk, and Rouen). These three industrial areas all have hazardous chemical and petrochemical industries in addition to other unhazardous industries. But, each has different socioeconomic characteristics and different perceptions of industrial risk. This case study relies on a rich dwelling-level micro-database in which each dwelling's address is precisely geocoded. We collect detailed data relative to the dwellings' extrinsic characteristics such as their proximity to a central business district, shops, and public utilities; and their exposure to industrial risk and to other risks or pollutions. The dwellings' price and intrinsic characteristics come from notarial data, and information about buyers and sellers is also provided.

Our first contribution is to study the impact of hazardous chemical and petrochemical industries on housing prices with rich microdata. Indeed, our unique database is much richer than those used by studies on the impact of similar industrial risks on housing prices. The impact of risk exposure on real estate prices is estimated for oil facilities by Boxall et al. (2005) and Flower and Ragas (1994), for the chemical industry by Caroll et al. (1996), and for industrial areas with chemical or petrochemical facilities by Sauvage (1997) and Travers et al. (2009). These studies use data with few (or without) extrinsic characteristics of the dwellings and without information on the buyers and sellers. ${ }^{1}$

\footnotetext{
${ }^{1}$ See Table 13 in Appendix A.2 for a review of all these studies and their data.
} 
Our second contribution is to apply our database to two models to compare the estimated impacts of the distance from hazardous plants on housing prices: a standard parametric model and a semiparametric model. The semiparametric regression is a locally weighted regression that allows implicit prices to vary with respect to space, time of sale, and the buyer's characteristics while keeping some smoothness in their distribution. This variation enables to relax and to test the assumption of the fixed parameters. With this approach, we find that the fixed-parameter assumption is rejected, which confirms the need for flexible forms and the use of semiparametric models. This study is the first to compare parametric and semiparametric models in the analysis of industrial risks, although this comparison has been used for other amenities; such as agricultural pollution (Bontemps et al., 2008) and light rail access (Redfearn, 2009). Anglin and Gencay (1996) also show that semiparametric hedonic models outperform parametric ones. McMillen (2010), McMillen and Redfearn (2010a), Redfearn (2009), and Sunding (2010) specifically compare parametric models with a locally weighted regression and recommend its use. Redfearn (2009) shows that implicit prices vary spatially and temporally and that assuming fixed implicit prices is a misspecification of the hedonic model. This misuse of parametric models has important consequences in our case study. Even though the signs and orders of the magnitude of the effects are similar in the two models for the very wide majority of coefficients, the estimated impacts of the distance from highly hazardous plants on housing prices significantly differs between the two models. The parametric model leads to an important bias (here an overestimation) in the estimated value of this impact near Bordeaux and Rouen and in its variations with respect to the distance from the plants near Rouen.

Using the semiparametric model, we show that the impact of hazardous plants on housing values strongly differs among the three industrial areas, even if they all surround chemical and petrochemical industries. The gunpowder factory near Bordeaux is a former military plant that was not necessarily perceived as hazardous by the neighboring population. We find that its proximity is even valued, probably because its neighborhoods are green and very quiet places. Thus, in this case, we capture the unobserved amenities that are spatially correlated with the distance from the plant. For Dunkirk and Rouen, chemical plants are clearly identified as hazardous by local populations. However, for Dunkirk, we find no significant impact of the distance from these plants on housing prices, likely because these industrial risks are overshadowed by the nuclear plant in Gravelines (located $18 \mathrm{~km}$ from 
Dunkirk). For Rouen, highly hazardous plants are perceived as disamenities: on average, households are willing to pay around $1.2 \%$ of their dwelling price to move 100 more meters away from these plants. This marginal willingness to pay decreases with respect to the distance from the plants, because the marginal gains (in terms of exposure reduction) of going further away from the hazard's source are likely to decrease. Further, we show that this marginal willingness to pay increases over time following accidents, information policies, or risk management laws.

Our results have practical implications. They show that parametric hedonic models can lead to an important bias in the estimated value of the marginal willingness to pay. Further, our results show that this estimated willingness to pay has a limited external validity: it strongly differs among industrial areas, even among chemical and petrochemical industries; it also depends on the distance from these facilities and on time. Thus, our findings call for the careful use of a population's willingness to pay for prevention against industrial risks in the cost-benefit analyses of prevention measures. Until now, most cost-benefit analyses have used the parameters taken from the estimation of parametric hedonic models and on other study areas and time frames than the ones under consideration in these analyses. This use can lead to a significant bias in the estimation of the efficient prevention level.

The paper is organized as follows. The parametric and semiparametric models are presented in Section 2. In Section 3, we describe the three industrial areas, the delimitation of the study areas, and the data. Section 4 contains the results from the parametric and semiparametric models. Section 5 concludes.

\section{Model}

Hedonic property models. Hedonic property models enable the estimation of the implicit price of the distance from highly hazardous plants (the first-order derivative of price with respect to this distance). This implicit price is equal to the households' (buyers' or sellers') marginal willingness to move one more meter away from these plants. Indeed, in the framework formalized by Rosen (1974), a dwelling is defined by its distance $d$ from a highly hazardous plant and several other characteristics $X$, which determine its price $P(d, X)$. When choosing their locations, households equalize their marginal willingness to pay for increasing each characteristic by one unit with the marginal, or implicit, price of 
this characteristic. ${ }^{2}$ Thus, the estimation of the hedonic price function provides an estimation of the implicit price of the distance $d$ from highly hazardous plants $\partial P(d, X) / \partial d$, which can be interpreted as the households' marginal willingness to pay to move one more meter away from highly hazardous plants.

Unless making very specific assumptions, the hedonic price function is not linear and has no known explicit form (see Freeman (2003) for a review of hedonic price methods). For this reason, we first perform the following parametric models: linear, log-linear, log-log, and linear with Box-Cox transformations of the price and continuous regressors while allowing these Box-Cox coefficients to be different (Grislain-Letremy and Katossky, 2013). For each of these specifications, we add fixed effects (municipality dummies) and test for different types of spatial dependency (spatial errors and/or spatial lag). A comparison by likelihood ratio tests of these nested models shows that a more flexible form is better (Grislain-Letremy and Katossky, 2013).

In addition to the baseline log-linear model, we use two extensions of this model: a parametric and a semiparametric model.

\subsection{Parametric model}

The parametric model is a log-polynomial model with municipality and time dummies based on an ordinary least squares. We estimate the logarithm of the price $P_{i}$ of dwelling $i$ as a function of the distance from the plants $d_{i}$, the dwelling's other characteristics $X_{i}$, and the vector $\eta_{t_{i}}$ of time dummies (for month and year of sale). In Bordeaux, the square and the cube of the distance from highly hazardous plants are significant and are included in the regression. For Rouen, only the square of the distance from highly hazardous plants

\footnotetext{
${ }^{2}$ Specifically, a household of income $y$ chooses its location by maximizing its utility $U(z, d, X)$, where $z$ denotes the amount of composite consumer good (which comprises all consumer goods except land), under its budget constraint $y=z+P(d, X)$. The location choices by households maximize their utilities by equalizing their marginal rates of substitution between each characteristic $\left(d\right.$ or $\left.x_{k}\right)$ and money with the implicit price of this characteristic $\left(\partial P(d, X) / \partial d\right.$ or $\left.\partial P(d, X) / \partial x_{k}\right)$ :
}

$$
\frac{U_{d}(z, d, X)}{U_{z}(z, d, X)}=\frac{\partial P(d, X)}{\partial d}, \quad \forall k, \frac{U_{x_{k}}(z, d, X)}{U_{z}(z, d, X)}=\frac{\partial P(d, X)}{\partial x_{k}} .
$$


is significant and is included in the regression.

$$
\begin{aligned}
\text { OLS Bordeaux: } & \ln P_{i}=\alpha+\beta_{1} d_{i}+\beta_{2} d_{i}^{2}+\beta_{3} d_{i}^{3}+\gamma^{\prime} X_{i}+\tau^{\prime} \eta_{t_{i}} \\
\text { OLS Dunkirk: } & \ln P_{i}=\alpha+\beta_{1} d_{i}+\gamma^{\prime} X_{i}+\tau^{\prime} \eta_{t_{i}} \\
\text { OLS Rouen: } & \ln P_{i}=\alpha+\beta_{1} d_{i}+\beta_{2} d_{i}^{2}+\gamma^{\prime} X_{i}+\tau^{\prime} \eta_{t_{i}}
\end{aligned}
$$

\subsection{Semiparametric model}

Motivation. The semiparametric model is also based on a log-linear specification. It is a locally weighted regression (LWR) that allows the marginal willingnesses to pay for characteristics to vary with respect to space, time of sale, and the buyer's characteristics while keeping some smoothness in their distribution. Indeed, the marginal willingness to pay for each characteristic is a priori not uniform over the study area (McMillen, 2010). The willingness can also vary after events that could have changed the risk perception, such as local or national accidents or information policies. For example, Gayer et al. (2000) and Kohlhase (1991) show that real estate prices can be significantly modified by information policies on hazardous waste facilities. ${ }^{3}$ The willingness can also vary after changes in insurance coverage. For example, flood insurance policies shape real estate prices (MacDonald et al. (1990), Harrison et al. (2001), Morgan (2007), and Bin et al. (2008)). Furthermore, the willingness to pay can vary among buyers because of heterogenous preferences, even though the proximity in terms of preferences might be already partly captured by geographical proximity because of sorting in the housing market.

McMillen (2010), McMillen and Redfearn (2010a), Redfearn (2009), and Sunding (2010) specifically compare parametric models with a locally weighted regression and affirm the use of this semiparametric model. Redfearn (2009) provides two main reasons that support the use of a locally weighted regression instead of the standard hedonic models: the rejected standard assumption of the fixed implicit prices and the presence of omitted local amenities. First, Redfearn (2009)'s results show that the standard assumption of the fixed implicit prices is rejected and suggest that imposing fixed parameters generates spatial patterns in the errors that lead to parameter estimates highly sensitive to very small changes in the sample or in the specification. Second, Redfearn (2009) compares the regressions with and without a known local amenity and shows that the local regression analysis appears more

\footnotetext{
${ }^{3}$ In the case of the disclosure of airport noise, Pope (2008) shows that publicly available information might not be adequately considered by all buyers. However, Currie et al. (2013)'s findings do not contradict perfect, or at least unbiased, information about industrial hazardous activities in the housing market, even in the presence of scientific uncertainty about health risks.
} 
robust to omitted local amenities.

Locally weighted regression: formalization. We estimate the logarithm of the price $P_{i}$ of dwelling $i$ as a function of the distance from the plants $d_{i}$, the dwelling's other characteristics $X_{i}$, and the vector $\eta_{t_{i}}$ of the dummies for the time of sale. We allow the coefficients to vary with respect to space ( $\mathrm{x}$ and $\mathrm{y}$ coordinates, $x c_{i}$ and $y c_{i}$ ), the time of sale $\left(t_{i}\right)$, and the buyer's income $\left(y_{i}\right)$ while keeping some smoothness in their distribution. We choose the buyer's income as its main characteristic. The income is imputed by using the gender, age, marital status, and the municipality of origin (Section 3); this way it summarizes the buyer's primary characteristics. ${ }^{4}$ By denoting $Z_{i}=\left(x c_{i}, y c_{i}, t_{i}, y_{i}\right)$, we get

$$
\text { LWR: } \ln P_{i}=\alpha\left(Z_{i}\right)+\beta\left(Z_{i}\right) d_{i}+\gamma^{\prime}\left(Z_{i}\right) X_{i}+\tau^{\prime}\left(Z_{i}\right) \eta_{t_{i}} .
$$

More precisely, the LWR is a set of weighted least square regressions with one regression for each observation (see McMillen and Redfearn (2010a) for a review). Each regression estimates the implicit prices at each observation by using a subsample of "close" observations. The proximity refers to spatial proximity, temporal proximity, as well as the proximity of the buyer's characteristics. The set of observations used in each local regression corresponds to the observations within a window around the considered observation $j .{ }^{5}$ Formally, the objective function for the estimation of the LWR is for observation $j$ :

$$
\text { LWR: } \sum_{i=1}^{n}\left(\ln P_{i}-\alpha-\beta d_{i}-\gamma^{\prime} X_{i}-\tau^{\prime} \eta_{t_{i}}\right)^{2} W_{i j},
$$

where $W_{i j}=f\left(Z_{i}, Z_{j}\right)$ is the weight for each observation $i$; this weight is a decreasing function of the spatial, temporal, and the buyer's distance from observation $i$ to the considered observation $j$.

Weights. First, we apply the Mahalanobis distance $d^{M}\left(Z_{i}, Z_{j}\right)$ between $Z_{i}$ and $Z_{j}$ to move from four dimensions to one dimension in our kernel: ${ }^{6}$

$$
d^{M}\left(Z_{i}, Z_{j}\right)=\sqrt{\left(Z_{i}-Z_{j}\right)^{T}(\operatorname{cov}(Z))^{-1}\left(Z_{i}-Z_{j}\right)}
$$

\footnotetext{
${ }^{4}$ We could have also allowed the marginal willingnesses to pay for characteristics to vary with respect to all primary characteristics of the buyers. But, in several parametric models, we do not get significant coefficients when the distance from the plant is crossed with the buyer's characteristics.

${ }^{5}$ Estimating numerous separate regressions for each observation could imply a high degree of freedom. This is not the case because of the smoothness implied by the overlapping samples (Redfearn (2009), see McMillen and Redfearn (2010a) for more details).

${ }^{6}$ Compared to the Euclidean distance, the Mahalanobis distance takes into account the correlations of the data set and is scale-invariant.
} 
where $Z=\left(Z_{1}, \ldots, Z_{n}\right)$. Then, the weights are generated by a kernel weighting function, the tri-cubic kernel weighting function, applied to this distance:

$$
W_{i j}=\left(1-\left(\frac{d^{M}\left(Z_{i}, Z_{j}\right)}{d_{\max }^{M}\left(Z_{i}, Z_{j}\right)}\right)^{3}\right)^{3},
$$

where $d_{m a x}^{M}\left(Z_{i}, Z_{j}\right)$ is the largest Mahalanobis distance from the considered observation $j$ to any observation within the window.

Window. Whereas the choice of the kernel function has a limited impact on the estimation results (McMillen, 2010), ${ }^{7}$ the choice of the window is crucial. The common window for all of the regressions can be chosen as a minimizer of the mean difference between the dependent variable and the estimated value over all of the regressions when excluding the considered observation from the sample. ${ }^{8}$ The size of the window estimated by cross-validation corresponds to $36 \%$ of the initial sample for Bordeaux, $40 \%$ for Dunkirk, $76 \%$ for Rouen. ${ }^{9}$ However, larger windows are needed when the objective is to measure the marginal effects and not to predict the dependent variable (McMillen, 2010). The larger windows are all the more needed that the interest variable (the distance from highly hazardous plants) varies with some kernel variables (the geographic coordinates): small windows can lead to imprecise estimates of the interest variable's marginal effect. These are the reasons why we use windows that correspond to $80 \%$ of the initial samples in the three areas. The significance and the mean value of the impact of our interest variable on the dwelling's value appear robust when considering smaller windows $(60 \%, 40 \%)$ with either tri-cubic or gaussian kernels.

\footnotetext{
${ }^{7}$ Results are robust when using a gaussian kernel function instead of a tri-cubic one.

${ }^{8}$ The LWR model can be written under a linear form (McMillen and Redfearn, 2010a). By denoting $Y_{i}=\ln \left(P_{i}\right)$, we get

$$
Y_{i}=L Y_{i}+u_{i}
$$

Thus, a cross-validation estimate of $h$ is a minimizer of the cross-validation measure $C V(h)$ :

$$
C V(h)=\frac{1}{n} \sum_{i=1}^{n}\left(\frac{Y_{i}-\hat{Y}_{h, i}}{1-l_{i i}}\right)^{2}
$$

where $\hat{Y}_{h, i}$ is the estimate based on the sample from which observation $i$ is removed and using a window of size $h$ around $i$.

${ }^{9}$ The initial samples comprise 1,423 observations for Bordeaux, 1,016 for Dunkirk, and 571 for Rouen. Thus, the size of the window estimated by cross-validation corresponds to 512 observations for Bordeaux, 406 for Dunkirk, and 434 for Rouen.
} 


\section{Industrial areas, study areas, and data}

In this section, we detail the selection of the industrial plants, the delimitation of the areas, and the collected variables.

\subsection{Industrial areas}

Many French hazardous industrial plants are surrounded by a high population density. However, the important work required by data collection limits the number of sites that could be studied. We choose three industrial areas because of the different socioeconomic characteristics of the surrounding neighborhoods and those neighborhoods' different perceptions of industrial risks.

Socioeconomic characteristics. The three industrial areas studied are located near important French cities: Bordeaux, Dunkirk, and Rouen (Figure 1). The three industrial

Figure 1: Location of Bordeaux, Dunkirk, and Rouen in France

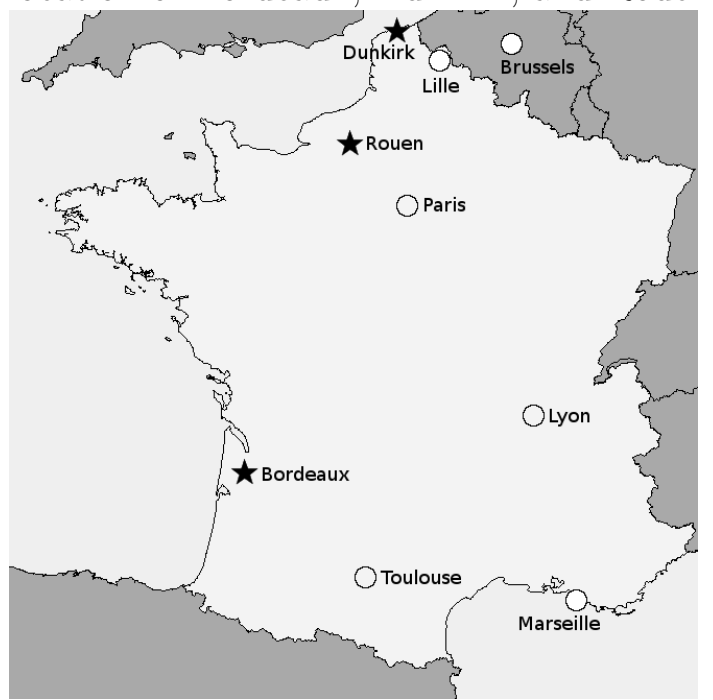

Source: Base map from Académie d'Aix-Marseille, production by authors.

areas present different socioeconomic characteristics (Table 1). The neighborhoods of the gunpowder industry near Bordeaux are the wealthiest; many of their inhabitants are executives in the aerospace industry. Dunkirk and its neighborhoods are the densest; many households are workers. The neighborhoods near Rouen are in an intermediate position between the first two areas: income is higher than near Dunkirk and lower than near Bordeaux; many inhabitants are executives and work far from their homes. According to the 2008 French annual declaration of social data, at best only $2 \%$ of the population in each municipality in the three areas is employed by the highly hazardous plants that are 
described below.

Table 1: Population's socioeconomic characteristics in the three studied areas

\begin{tabular}{|c|c|c|c|c|c|c|c|}
\hline Municipality & $\begin{array}{l}\text { INSEE } \\
\text { code }\end{array}$ & $\begin{array}{l}\text { Population } \\
\text { (a) }\end{array}$ & $\begin{array}{l}\text { Population } \\
\text { density (a) } \\
\text { (per sq km) }\end{array}$ & $\begin{array}{l}\text { Percentage } \\
\text { of built } \\
\text { area (b) }\end{array}$ & $\begin{array}{c}\text { Average tax } \\
\text { revenue (a) } \\
\quad(\text { euro) }\end{array}$ & $\begin{array}{c}\text { Sports and } \\
\text { sociocultural } \\
\text { facilities (c) }\end{array}$ & $\begin{array}{l}\text { Distance } \\
\text { from labor } \\
\text { pool (d) }\end{array}$ \\
\hline \multicolumn{7}{|c|}{ Near Bordeaux } & $(\mathrm{km})$ \\
\hline Le Haillan & 33200 & 8,378 & 904 & 8 & 26,817 & 14 & 5.9 \\
\hline Martignas-sur-Jalles & 33273 & 6,633 & 251 & 2 & 29,005 & 27 & 9.2 \\
\hline Mérignac & 33281 & 65,469 & 1,359 & 9 & 23,181 & 72 & 4.4 \\
\hline Saint-Aubin-de-Médoc & 33376 & 5,550 & 159 & 1 & 41,577 & 12 & 11.1 \\
\hline Saint-Médard-en-Jalles & 33449 & 26,984 & 315 & 3 & 27,599 & 48 & 4.8 \\
\hline Le Taillan-Médoc & 33519 & 8,668 & 571 & 5 & 30,412 & 14 & 4.9 \\
\hline \multicolumn{8}{|c|}{ Near Dunkirk } \\
\hline Coudekerque-Branche & 59155 & 22,994 & 2,515 & 11 & $\overline{18,641}$ & 23 & 4.3 \\
\hline Dunkirk & 59183 & 69,274 & 1,855 & 12 & 20,218 & 18 & 4.1 \\
\hline Fort-Mardyck & 59248 & 3,586 & 2,543 & 13 & 18,610 & 7 & 9 \\
\hline Saint-Pol-sur-Mer & 59540 & 22,100 & 4,299 & 16 & 14,711 & 14 & 6.2 \\
\hline \multicolumn{8}{|c|}{ Near Rouen } \\
\hline Grand-Couronne & $\overline{776319}$ & 9,346 & $\overline{552}$ & 5 & $\overline{20,083}$ & 18 & 20.5 \\
\hline Hautot-sur-Seine & 76350 & 9,346 & 160 & 1 & 26,423 & 2 & 19.3 \\
\hline Moulineaux & 76457 & 881 & 238 & 2 & 21,287 & 10 & 20.6 \\
\hline Petit-Couronne & 76497 & 8,690 & 679 & 5 & 19,638 & 28 & 21.1 \\
\hline Sahurs & 76550 & 1,310 & 117 & 1 & 27,017 & 5 & 26.8 \\
\hline Val-de-la-Haye & 76717 & 751 & 74 & 1 & 23,673 & 5 & 20.5 \\
\hline
\end{tabular}

Note: The municipalities of Fort-Mardyck and Saint-Pol-sur-Mer were attached to the Dunkirk municipality in 2010.

Sources: (a) French National Institute for Statistics and Economic Studies (INSEE), (b) building database of the Geographical National Institute, (c) topology database of the Geographical National Institute, (d) Sitranet.

Risks and perceptions of industrial areas. The official classification of hazardous plants is defined by regulation. The Seveso II Directive (Council directive 96/82/EC on the control of major-accident hazards) defines hazardous industries according to the presence and degree of hazardous substances or preparations. The regulation categorizes the plants with respect to the nature and quantities of the hazardous substances as "upper tier" and "lower tier" sites. The French legislation is actually harsher than the European one: the French classification includes many other far less hazardous sites, called "authorized" plants.

The three industrial areas in this study include hazardous chemical and petrochemical industries. However, they present different industrial activities and very different perceptions of the associated risks by the local populations. The gunpowder factory near Bordeaux was settled in 1660. The municipalities in the neighborhoods were initially developed thanks to this factory. Later, the urban development was explained by the attraction to Bordeaux's center. Today, the gunpowder comprises two "upper tier" sites as defined by the Seveso 
II Directive. By manufacturing gunpowder and explosives, the factory mainly exposes the local population to the risk of explosion. However, it is not necessarily perceived as hazardous by the neighboring population because it was a former military plant. In many parts of the neighborhoods only barbed wire can be seen. Furthermore, as the plant is large (650 buildings over 350 hectares), the risk is relatively "contained" within the industrial site. The only nuisance associated with the plant is the transportation of the hazardous materials on a precise and limited route.

In contrast, the chemical activities near Dunkirk and Rouen are clearly identified as hazardous by the local populations. In Dunkirk, after World War II, urbanization was realized around industrial areas that were not perceived as hazardous (shipyards, steel industry); hazardous plants (chemistry, petrochemistry) appeared in Dunkirk harbor only in the 1970s. There are now 16 hazardous plants: 14 "upper tier" Seveso sites and two authorized sites. Their activities consist of the storage and refining of oil products, metallurgy, the manufacture of industrial gases and of chemical and pharmaceutical products, and waste treatment. These industries expose the local population to risks of explosion, fire and toxic pollution. The plants (either buildings, chimneys, or at least plumes of smoke) can be seen from every neighborhood dwelling. However, the presence of a nuclear plant in Gravelines (18 km from Dunkirk) might overshadow the exposure to these industrial risks.

Near Rouen, some plants were established in the 1920s and 1930s. However, the majority of the plants progressively appeared between the 1960s and the 1990s, and urban areas simultaneously extended while becoming closer and closer to these different plants. There are now 13 hazardous plants: two "upper tier" Seveso sites, one "lower tier", and ten authorized Seveso sites. Their activities are quite diverse: storage and refining of liquid petroleum gas, production of Diester oil (biodiesel) and of liquid carbon dioxide, perfume storage, paper manufacture, goods transportation, and warehouses. They expose the local population to the same risks as in Dunkirk: explosion, fire, toxic pollution. Because of the landscape, chimneys and silos cannot be seen from some neighborhood dwellings.

Although all these highly hazardous plants were established well before the study period, several other events, either local or national, might have modified the risk perceptions between 2000 and 2008. We detail all these local and national events in Table 2. Local events are accidents and local policies. Only one accident happened near Dunkirk. On 
January 12, 2007, the neighboring populations saw flames and plumes of smoke at the Rubis Terminal (storage of liquid flammable and agrochemical products). The accident triggered an emergency plan inside the plant and required the intervention of civil fire brigades. ${ }^{10}$ Local policies included the distribution of information leaflets, the update of the emergency plan for households, and the implementation of local committees for information and consultation. The national events consist of the AZF accident in 2001 in Toulouse and the implementation of a risk management law during the study period. The AZF accident, which is the major industrial accident in France in the last decades, appears to have left a particularly deep and long-lasting impression near Rouen because one of the plants in this study, Grande Paroisse Normandy, has a very similar activity to the AZF plant and belongs to the same company, Grande Paroisse (a subsidiary of Total group). ${ }^{11}$ This accident precipitated the 2003 law that created in particular the technological disasters insurance system, which improves the coverage of households, and the technological risk prevention plans, which were implemented after the study period in each of the three areas.

Table 2: Local and national events that may have modified industrial risk perception during the study period (2000-2008)

\begin{tabular}{|c|c|c|c|c|}
\hline Year & Bordeaux & Dunkirk & Rouen & National level \\
\hline 2001 & - & - & - & AZF accident \\
\hline 2002 & - & Information leaflets & - & - \\
\hline 2003 & - & - & - & Law \\
\hline 2004 & - & $\begin{array}{l}\text { Update of the emergency } \\
\text { plan for households }\end{array}$ & - & - \\
\hline 2005 & - & - & $\begin{array}{l}\text { Creation of local } \\
\text { committee for information } \\
\text { and consultation }\end{array}$ & - \\
\hline 2006 & - & $\begin{array}{c}\text { Creation of local } \\
\text { committee for information } \\
\text { and consultation } \\
+ \text { information leaflets } \\
\text { about the emergency plan } \\
\text { for households }\end{array}$ & - & \\
\hline 2007 & - & Accident & $\begin{array}{l}\text { Information leaflets } \\
\text { about the emergency plan } \\
\text { for households }(*)\end{array}$ & - \\
\hline
\end{tabular}

Note: $(*)$ In all municipalities except Moulineaux.

Source: Reports by the Technical Studies Center of Public Works of Normandy and Centre, Nord and Picardy, and South West France.

\footnotetext{
${ }^{10}$ After the study period, other accidents occurred. In the gunpowder factory near Bordeaux, a fire caused one death and seriously injured two people in December 2013 ("Gironde : un mort et deux blessés dans un incendie sur un site classé Seveso" by Jean-Pierre Tamisier, December 6th, 2013, Sud-Ouest); near Rouen, mercaptan gas escaped from one of the factories, the Lubrizol company, and caused a foul odor in France and in England in January 2013 ("Foul-Smelling Cloud Drifts Over France, Alarming Residents" by Scott Sayare, January 22nd, 2013, The New York Times).

11""Grande-Paroisse" à Rouen, un site Seveso hanté par le spectre d'AZF" by Audrey Garric, February 5, 2013. Le Monde.fr.
} 


\subsection{Delimitation of study areas}

In order to measure the impact of the distance from plants on housing values, the study area has to be broad enough to include dwellings close to and far from the plants. However, as Redfearn (2009) notes, "expanding the geographic scope of the sample is likely to draw additional omitted amenities and/or more submarkets." In order to limit the number of collected characteristics of the dwellings and to avoid districts in which the neighborhood quality is difficult to capture, areas such as the central business district and a few atypical districts, corresponding to less than $5 \%$ of the samples, are excluded. For example, the following is the selection of districts for Dunkirk, where this selection is the most important. We exclude the highly attractive districts that are the Téteghem municipality (the select residential suburb of Dunkirk), the historic center, and the sandbar in the east of the urban area (Dunkirk-Darses and Dunkirk-Malo-les-Bains). The unattractive districts such as Mardyck village and Grande Synthe municipalities are also excluded. The Grande Synthe municipality is an urban renewal zone where housing prices are relatively low because of civil insecurity (petty crime and acts of violence), but this low neighborhood quality is difficult to capture. Finally, the Leffrinckoucke municipality is excluded because of the presence of a small hazardous plant that emits a black plume of smoke; this plant can overshadow the other studied hazardous plants.

The chosen study areas comprise dwellings very close to the plants and as far away as 10 $\mathrm{km}$ for Bordeaux, $4 \mathrm{~km}$ for Dunkirk, and $5 \mathrm{~km}$ for Rouen (Table 10 in Appendix A.1 and Figures 2, 3 and 4). The majority of the literature that studies the impact of industrial risks on housing prices uses similar study areas (Table 13 in Appendix A.2).

\subsection{Data collection}

Our analysis requires data on the price and characteristics of the dwellings, and the characteristics of the buyers and sellers (Table 3). The price of the dwelling and its intrinsic characteristics (state, living space, number of rooms, etc.) come from the PERVAL notarial data for the years 2000, 2002, 2004, 2006, and 2008. Thus, only the dwelling purchases (as opposed to rents) can be studied. We consider transactions only between households. Furthermore, we restrict our analysis to houses (as opposed to apartments), because they represent a homogeneous market. ${ }^{12}$ Each dwelling's address is precisely geocoded. Detailed data relative to the dwellings' extrinsic characteristics are collected: commuting time (by

\footnotetext{
${ }^{12}$ Houses make up the majority in our sample: $83 \%$ of houses for Bordeaux, $87 \%$ for Dunkirk, and $72 \%$ for Rouen.
} 


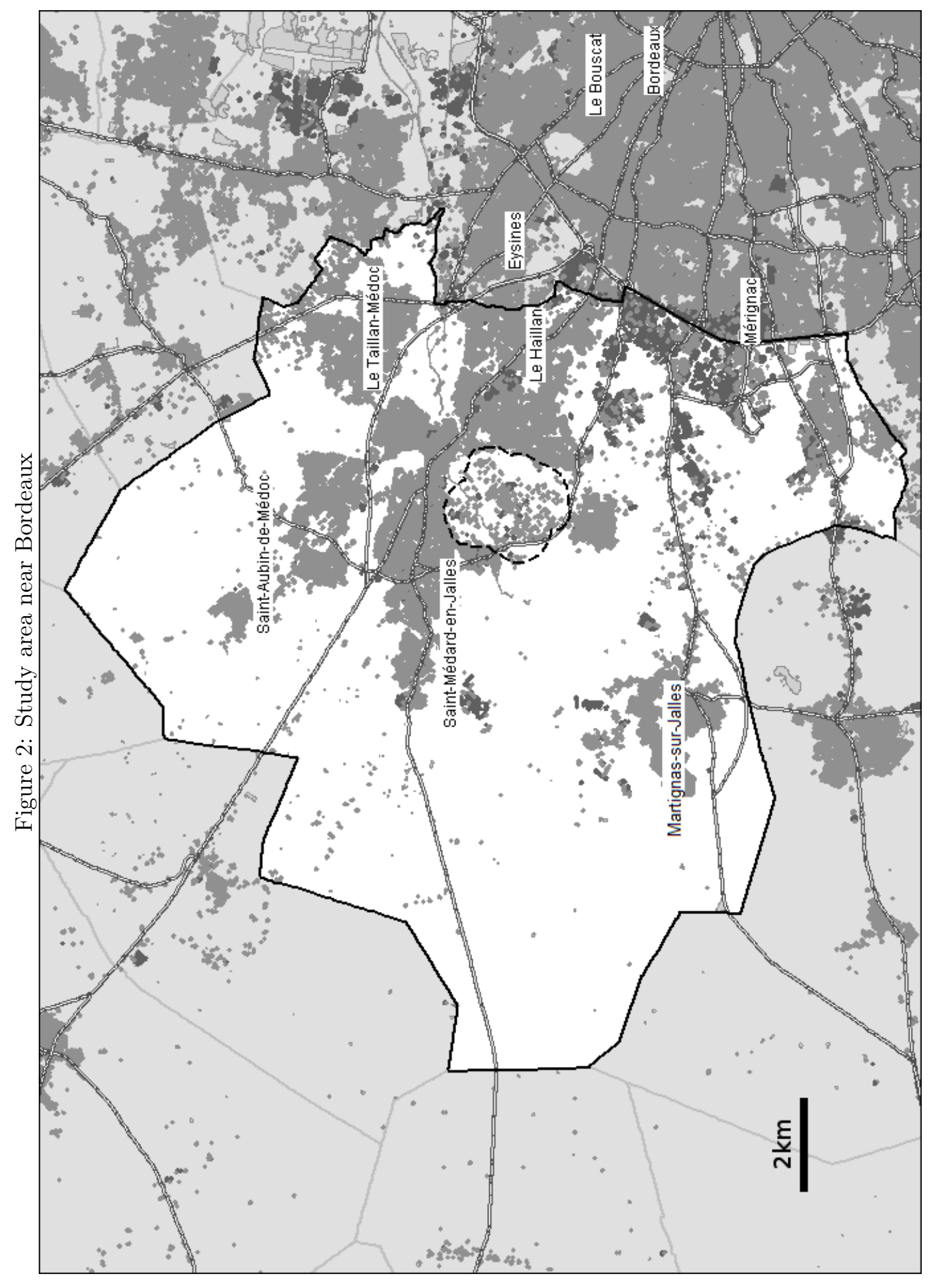

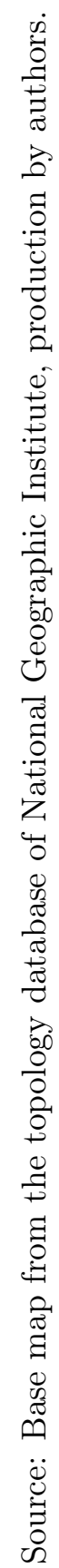




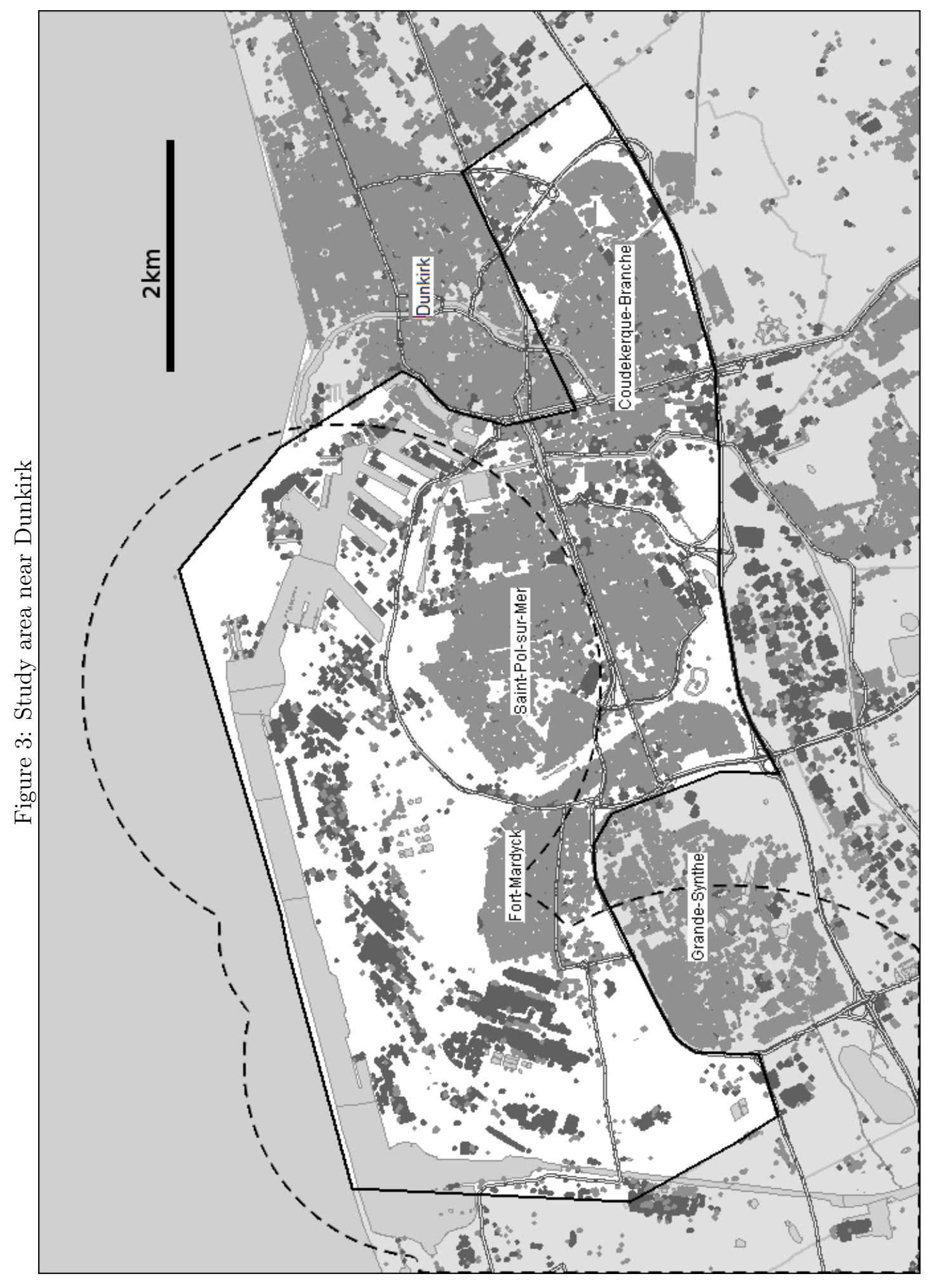

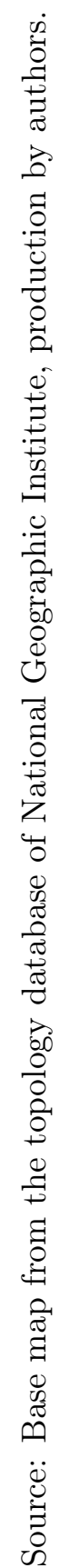




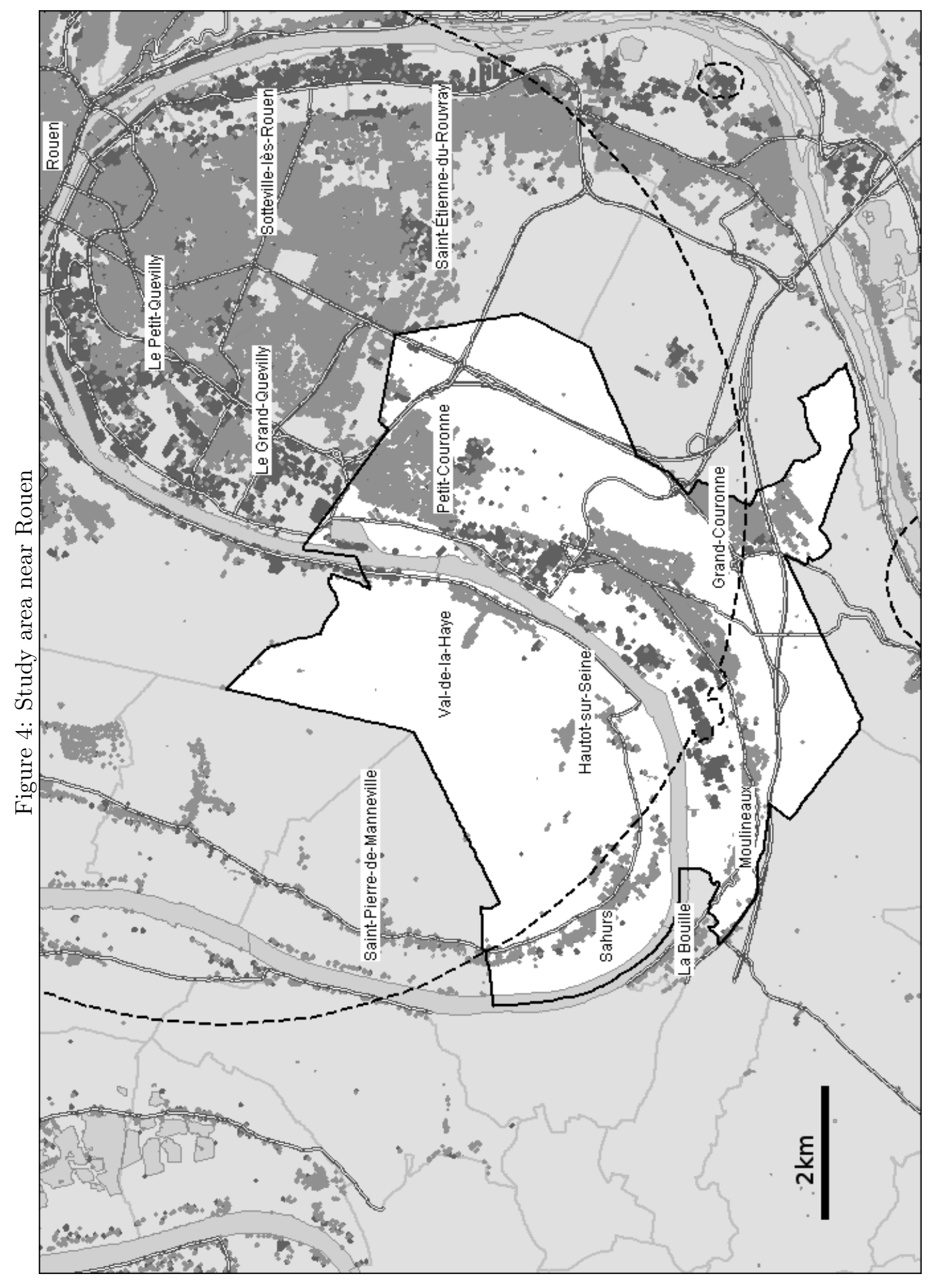

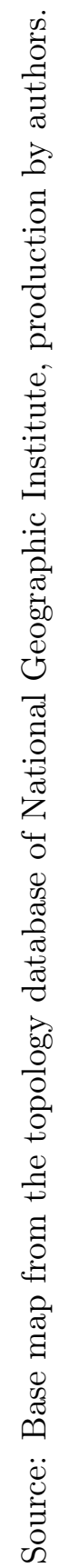


car) from central business district, distance from shops and public utilities, and exposure to industrial risk and to other risks or pollutions. The database from the French solicitors also provides information about the buyers and sellers: their gender, their age, their social and occupational group, their marital status, and their municipality of origin. The annual income is matched with the gender, age, marital status, and municipality of origin and comes from the General Directorate of Public Finances for the period of 2004 to $2008 .{ }^{13}$

Our database is unique and much richer compared to those in the literature that study the impact of similar industrial risks on housing prices (Table 13 in Appendix A.2). These studies use data with a similar number of observations but with few (or without) extrinsic characteristics of the dwellings and without information on the buyers and sellers. Our samples comprise 1,423 observations for Bordeaux, 1,016 for Dunkirk, and 571 for Rouen. Further, in the chosen study areas, the transactions within each jurisdiction are relatively uniformly distributed over the study period (Table 12 in Appendix A.1). The detailed descriptive statistics are provided in Appendix A.1 (Tables 9, 10, and 11).

Our key variable of interest is the distance from the dwelling to highly hazardous plants (mainly Seveso sites, "upper tier" and "lower tier" ones). We also consider the distance from "authorized plants" (subject to the French regime of classified plants for the environment's protection) and the locations in risk management areas. The risk management areas are the emergency planning zones for households and areas of control for future land use: the exclusion area, called "Z1 area", corresponds to the area with lethal damages in case of an accident; "Z2 area" is the area where new buildings are allowed but limited and corresponds to irreversible damages. Because these zones are very limited, they have a small number of transactions during the study period (Table 10 in Appendix A.1). Finally, because the hazardous plants near Rouen present the specificity of not being visible from some dwellings, we consider the dummy for the view of plants from a dwelling for Rouen. This choice of variables to quantify perceived exposure to industrial risk is consistent with other studies on the impact of similar industrial risks on housing prices. All of these studies use the effective distance between the dwelling and the plant (Table 13 in Appendix A.2).

\footnotetext{
${ }^{13}$ For Bordeaux, $3 \%$ of the observations do not include any information on the buyers (or only their municipality of origin) and are excluded from the sample. For Dunkirk, $6 \%$ of the observations do not provide the gender, age, or marital status of the buyers and are excluded; the social and occupational group is missing for $30 \%$ of the remaining observations. For Rouen, $9 \%$ of the observations do not include any information on the buyers (or only their municipality of origin) and are excluded from the sample. Besides, in each area, we exclude only a few foreign buyers (less than 1\%) for whom we could not match the income.
} 
Some studies add other variables, such as dummies for location in administrative areas for risk management (emergency plans such as in Boxall et al. (2005) and Travers et al. (2009)) or variables traducing the perception of pollution created by the plant (Boxall et al. (2005), Sauvage (1997)).

Table 3: Data

\begin{tabular}{|c|c|c|}
\hline \multicolumn{3}{|c|}{ Dwellings' characteristics } \\
\hline Intrinsic characteristics $(\mathrm{a})$ & Extrinsic characteristics & \\
\hline Price (including tax) & Distance and commuting time (by car) & \\
\hline House or apartment & from the central business district $(*)$ & (b) ,(f) \\
\hline Less than 5 years old & Distance from the market square & $(\mathrm{c}),(\mathrm{d})$ \\
\hline Condition & Distance from a drugstore & $(\mathrm{c}),(\mathrm{d})$ \\
\hline Living space & Distance from a food shop & $\begin{array}{l}\text { (c), } \\
\text { (d), (e) }\end{array}$ \\
\hline Number of rooms & Distance from a bus stop & (f) \\
\hline Number of bathrooms & Distance from a park & (f) \\
\hline Number of parking spaces & Distance from a nursery or primary school & $(\mathrm{e}),(\mathrm{g})$ \\
\hline Presence of a terrace & Distance from a high school & $(\mathrm{e}),(\mathrm{g})$ \\
\hline Presence of a balcony & Distance from the nearest highly hazardous plants $(\dagger)$ & (h) \\
\hline Presence of an elevator & Distance from the nearest authorized plants $(\ddagger)$ & (h) \\
\hline Presence of a swimming pool & View of industrial plants (for Rouen) $(\diamond)$ & (g) \\
\hline Presence of a basement & Location in a land use control area (Z1, Z2) & (i) \\
\hline Presence of a cellar & Location in an area of emergency plan for households & (j) \\
\hline Presence of annexes & Location in an area exposed to natural hazards $(\triangleright)$ & (i) \\
\hline Presence of outbuildings & Location in an area exposed to other hazards $(\triangleright)$ & (i) \\
\hline Presence of an attic & Location in a residual pollution area & $(\mathrm{k})$ \\
\hline \multirow[t]{5}{*}{ Total acreage } & Location in an environmental protection area & (i) \\
\hline & Location in a conservation easement area & (i) \\
\hline & Sound exposure to a land transport facility & $(\mathrm{l}),(\mathrm{m})$ \\
\hline & Sound exposure to an air transport facility & $(\mathrm{l}),(\mathrm{m})$ \\
\hline & \multicolumn{2}{|l|}{ Buyers' and sellers' characteristics $(\triangleleft)$} \\
\hline Income & & (n) \\
\hline Gender & & (a) \\
\hline Age & & (a) \\
\hline Social and occupational group & & (a) \\
\hline Marital status & & (a) \\
\hline Municipality of origin & & (a) \\
\hline
\end{tabular}

Sources: (a) PERVAL, (b) geographic directory of municipalities, (c) Chambers of Commerce and Industry database, (d) municipal database, (e) phone book, (f) topology database of the National Geographical Institute, (g) building database of the National Geographical Institute, (h) database for classified plants per municipality, (i) land use plan, (j) prefecture, (k) Regional Office for Environment, Planning and Housing, (l) sound map of the Departmental Office for Territories and Sea, (m) sound map of the Technical Studies Center of Public Works, (n) statements of income from the General Directorate of Public Finances.

Notes: Each distance from a facility is built as the distance from the closest facility.

(*) Distance or commuting time from the central business district is computed as the distance or commuting time from the town hall of Bordeaux, Dunkirk, or Rouen.

$(\dagger)$ Most hazardous plants are among the classified plants for the environment's protection (mainly Seveso sites).

$(\ddagger)$ Plants subject to the regime of classified plants for the environment’s protection.

$(\diamond)$ View from the dwelling of red and white Petroplus chimney or of Senalia silo.

$(\triangleright)$ Area of servitude or notification.

$(\triangleleft)$ This information is relative to the individual buyer (or seller) or to the household reference person. 


\section{Results}

We estimate the hedonic price function with three different models: the baseline parametric OLS log-linear model and two extensions of this model, a parametric OLS log-polynomial model, and a semiparametric LWR log-linear model (Section 2). The results of these hedonic regressions are presented for Bordeaux in Table 4, for Dunkirk in Table 5, and for Rouen in Table $6 .{ }^{14}$ As expected, being recently built; in good condition; living space; numbers of rooms, bathrooms, and parking spaces; and total acreage all increase the dwelling's value. The presences of outbuildings, a basement, and a swimming pool can also increase the dwelling's price. Because variations in commuting times are limited (Table 10 in Appendix A.2), and with the addition of municipality dummies in parametric models, the commuting time from the central business district does not significantly modify the dwelling's value. ${ }^{15}$ In the three models, the signs are the same and the orders of magnitude are similar.

\subsection{Different impacts of the distance from highly hazardous plants be- tween the studied areas}

Even among the same category of industries (chemical and petrochemical industries), the impact of the distance from highly hazardous plants on the dwelling's value varies between the three areas. For Bordeaux, in all of the models, the proximity to the gunpowder factory is valued by the inhabitants in close vicinity (Table 4), probably because the neighborhoods around the plant are green with many trees and are very quiet. ${ }^{16}$ Thus, we capture unobserved amenities that are spatially correlated with the distance from the plant.

For Dunkirk, the semiparametric model reveals that the distance from highly hazardous plants does not significantly impact housing prices (Table 5). Indeed, the presence of a nuclear plant in Gravelines (located $18 \mathrm{~km}$ from Dunkirk) likely overshadows the exposure to other industrial risks. On the contrary, the parametric model indicates that the distance from highly hazardous plants increases the housing prices in Dunkirk. This difference is

\footnotetext{
${ }^{14}$ Parametric regressions include municipality dummies and year and month dummies. For the sake of readability, these estimated coefficients are not reported. Some of them are significant at the $1 \%$ or the $5 \%$ level.

${ }^{15}$ When excluding the municipality dummies, the commuting time is significant in all of the parametric models. In the semiparametric ones, this effect is captured by the distribution of intercepts, as the intercept is allowed to vary with respect to the kernel variables, in particular the geographic coordinates. All these results are similar when using the geographic distance from central business district instead of the commuting time.

${ }^{16}$ These green areas do not belong to parks. This is why this effect is not captured by the observed distance from parks.
} 
due, not to the nature of the model used, but to the size of the sample used for the regressions. For Dunkirk, the main part of the sample is almost uniformly concentrated between $700 \mathrm{~m}$ and $3 \mathrm{~km}$ from the highly hazardous plants. In the semiparametric regression, the extreme observations are rarely used and weigh less than the others; but in the parametric regression, the whole sample is used and each observation has an equal weight. When restricting the observations to between $700 \mathrm{~m}$ and $3 \mathrm{~km}$, the parametric regression shows that the distance from the highly hazardous plants does not significantly impact housing prices.

For Rouen, in all of the models, the distance from highly hazardous plants increases the dwellings' values (Table 6): the highly hazardous plants are perceived as disamenities. The magnitude of this impact is important: on average, the households are willing to pay around $1.2 \%$ of their dwelling's price to move 100 more meters away from the highly hazardous plants in Rouen (Table 7). This order of magnitude is consistent with other studies relative to the impact of similar industrial risks on housing prices (Table 13 in Appendix A.2).

Reviewing other similar studies shows that the distance from hazardous plants can increase, decrease, or have no significant impact on housing prices, depending on the studied case and in particular on the type of industries (Table 13 in Appendix A.2). Clark and Nieves (1994) also show that the proximity to a petrochemical refinery weighs more on the housing prices than the proximity to coal, gas, or oil-fired plants; to hazardous waste; or to a liquefied natural gas site. Our results confirm this dependency on the studied case, which is here mainly due to the differences in the perception of industrial activities and of their neighborhoods.

\subsection{Testing the fixed-parameter assumption}

When comparing the parametric model and the baseline log-linear model, the square or the cube of the distance from highly hazardous plants are significant in the parametric model for Bordeaux and Rouen (Tables 4 and 6). This significance suggests that the fixedparameter assumption does not hold. The fixed-parameter assumption is properly tested by comparing the semiparametric model and the baseline log-linear model, which corresponds to a nested model under the null hypothesis of fixed coefficients. ${ }^{17}$ This hypothesis is rejected at the $0.01 \%$ level, which supports both the use of the flexible forms and the

\footnotetext{
${ }^{17}$ See McMillen and Redfearn (2010a) for a summary of Cleveland and Devlin's F-test and its adaptation to the LWR regression.
} 


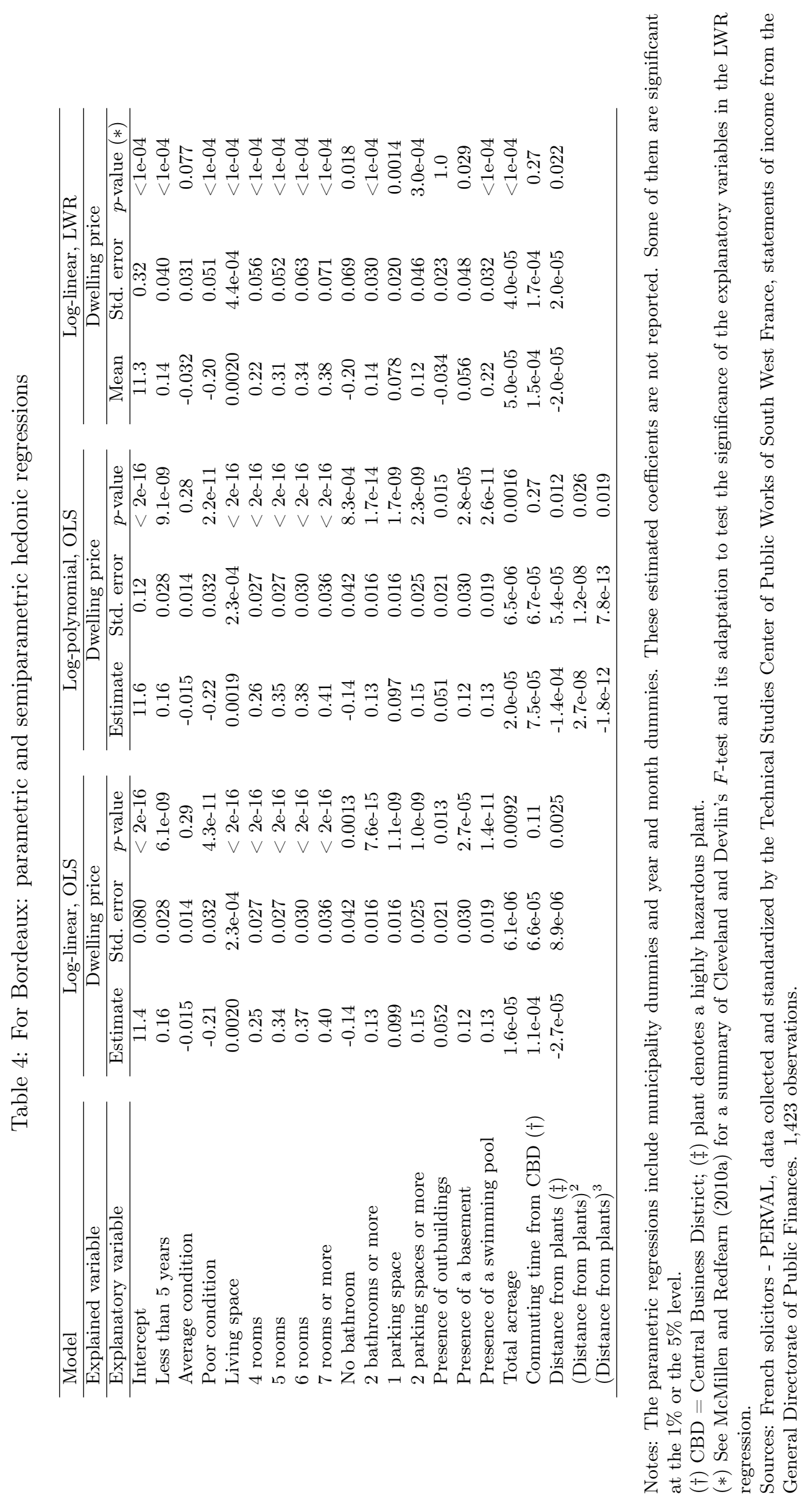




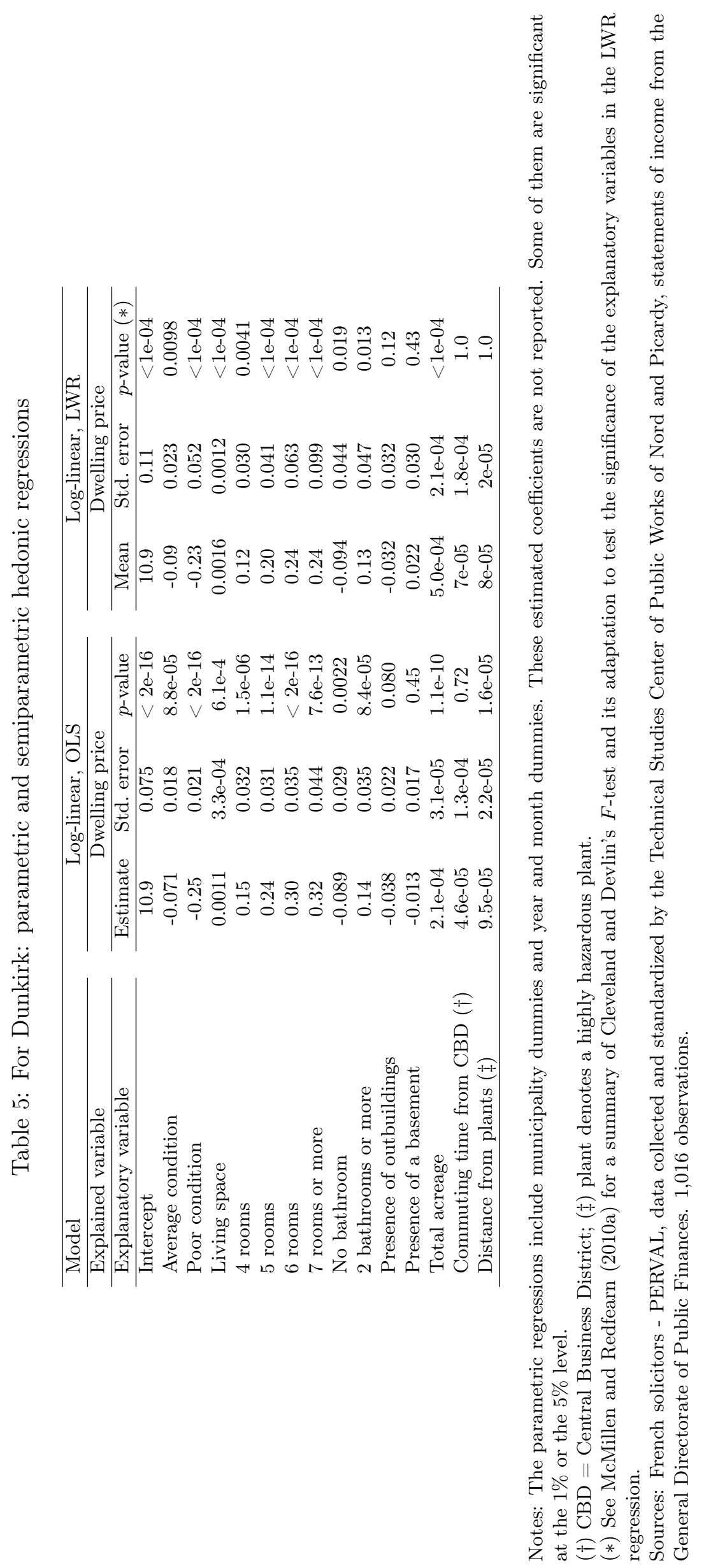




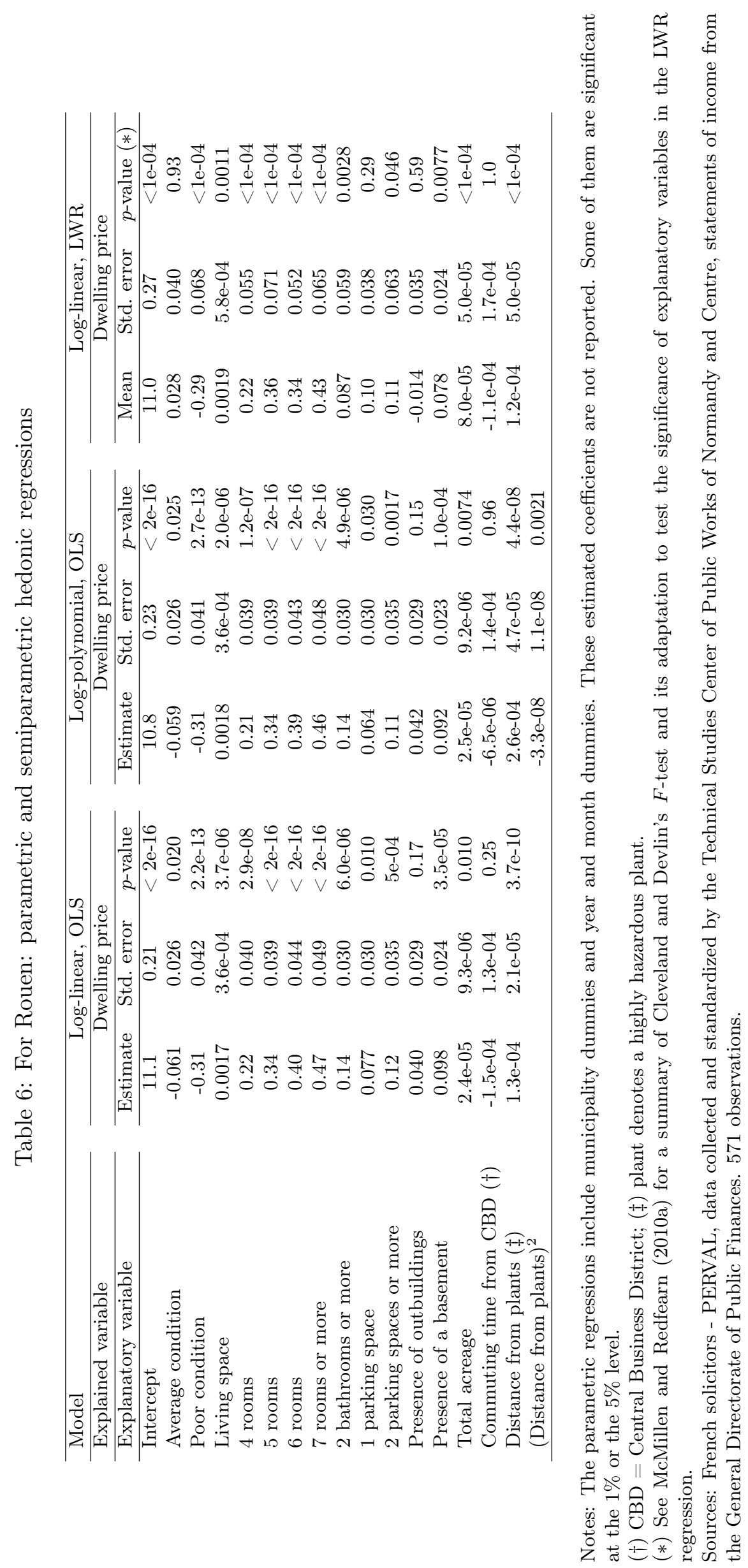


semiparametric model.

\subsection{Comparing the impacts of the distance from plants estimated by the parametric and semiparametric models}

We compare the estimated impacts of the distance from the plants provided by the parametric log-polynomial model and by the semiparametric model.

Value. Parametric log-polynomial regressions lead to a bias in the estimated value of the impact of the distance from highly hazardous plants on dwelling prices for Bordeaux and Rouen. The implicit price of distance $d$ from these plants equals the absolute marginal willingness to pay $A M W T P$ to move one more meter away (Section 2). To make comparisons between the dwellings or between the three areas easier, we also compute the relative willingness to pay $R M W T P$ to move 100 more meters away from the plants (expressed as a percentage of the dwelling's price).

$$
\begin{aligned}
& A M W T P=\frac{\partial P(X)}{\partial d} \\
& R M W T P=\frac{\partial P(X)}{\partial d} \frac{\Delta d}{P} \text { with } \Delta d=100 .
\end{aligned}
$$

Table 7 properly compares the absolute and relative marginal willingnesses to pay, as estimated by the parametric and semiparametric models.

The parametric model leads to a biased estimation of the average marginal willingness to pay over the sample, be it the absolute willingness or the relative one, for Bordeaux and Rouen. For Rouen, the parametric model leads to a clear overestimation: the means of the absolute and the relative marginal willingnesses to pay are $31 \%$ and $39 \%$ respectively higher than as estimated by the semiparametric one (Table 7). However, the model's bias could lead either to an overestimation or to an underestimation of the average marginal willingness to pay. Indeed, the semiparametric model gives a higher weight to sets of "close" observations (proximity being defined by the kernel in terms of location, time, and income), whereas the parametric model gives an equal weight to each observation. ${ }^{18}$ If, as here, these sets of "close" observations correspond to a lower marginal willingness to pay than the average, the parametric model leads to an overestimation of the average marginal willingness to pay.

\footnotetext{
${ }^{18}$ The OLS can be considered as a special case of the LWR: it is a LWR with a window size of $100 \%$ (the whole sample) and a weight equal to $1 / n$ everywhere, $n$ denoting the sample size.
} 
Table 7: Households' marginal willingness to pay to move one more meter away from the highly hazardous plants

\begin{tabular}{|c|c|c|c|c|c|c|}
\hline & \multicolumn{3}{|c|}{$\begin{array}{l}\text { MWTP estimated by } \\
\text { log-polynomial, OLS }\end{array}$} & \multicolumn{3}{|c|}{$\begin{array}{l}\text { MWTP estimated by } \\
\text { log-linear, LWR }\end{array}$} \\
\hline & Median & Mean & Std. Dev. & Median & Mean & Std. Dev. \\
\hline \multicolumn{7}{|l|}{ For Bordeaux } \\
\hline $\operatorname{AMWTP}(€ / \mathrm{m})$ & -3.65 & -5.32 & 5.24 & -3.36 & -3.17 & 3.89 \\
\hline RMWTP $(\% / 100 \mathrm{~m})$ & -0.19 & -0.25 & 0.21 & -0.19 & -0.20 & 0.21 \\
\hline \multicolumn{7}{|l|}{ For Dunkirk } \\
\hline $\operatorname{AMWTP}(€ / \mathrm{m})$ & 9.45 & 10.00 & 3.91 & - & - & - \\
\hline RMWTP $(\% / 100 \mathrm{~m})$ & 0.95 & 0.95 & 0 & - & - & - \\
\hline \multicolumn{7}{|l|}{ For Rouen } \\
\hline $\operatorname{AMWTP}(€ / \mathrm{m})$ & 19.33 & 20.25 & 11.16 & 14.39 & 15.44 & 9.91 \\
\hline $\operatorname{RMWTP}(\% / 100 \mathrm{~m})$ & 1.88 & 1.67 & 0.68 & 1.22 & 1.20 & 0.51 \\
\hline
\end{tabular}

Notes: In the parametric regression, the log of price is explained by the linear expression of the dwelling characteristics and by a polynomial of the distance from the plants (Equation 4). In the semiparametric regression, the log of price is explained by the linear expression of the dwelling characteristics while allowing the coefficients to vary with respect to $Z_{i}$, that is, with respect to the geographic coordinates, time, and the buyer's income (Equation 6). Thus, we get

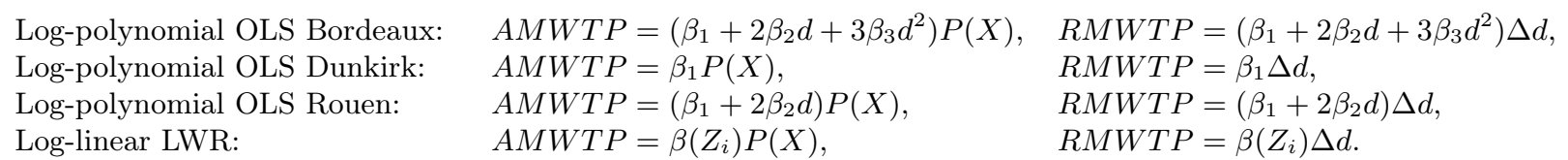

For Dunkirk, the willingnesses to pay as estimated by the LWR are not provided because the distance from the nearest highly hazardous plant is not significant in this model.

Sources: French solicitors - PERVAL, data collected and standardized by the Technical Studies Center of Public Works of Normandy and Centre, and statements of income from the General Directorate of Public Finances. 1,423 observations for Bordeaux, 1,016 for Dunkirk, and 571 for Rouen. 
Variations. For Rouen, the parametric model also leads to a biased estimation (here again a clear overestimation) of the variations in the relative marginal willingness to pay with respect to the distance from plants. ${ }^{19}$

We perform regressions that correspond to the second step of Rosen (1974)'s method. The first step is the main hedonic price regression: it estimates the dwelling price $P(X)$ depending on the dwelling characteristics $X$ (Table 6 in Section 4). The second step consists of using the implicit price $\left(\partial P(X) / \partial x_{k}\right)_{k}$ estimated in the first step, by either the parametric or the semiparametric model, to recover the information relative to demand and supply. More precisely, we explain the marginal willingness to pay as estimated by the semiparametric regression with the distance from plants, year dummies, and the buyer's income; and also his or her age, gender, social and occupational group, marital status, and location of origin (Table 8). We explain the marginal willingness to pay as estimated by the log-polynomial parametric regression with the distance from the plants (Table 8). ${ }^{20}$

These regressions must be considered as essentially descriptive because they explain the willingness to pay to move away from the plants (the marginal price of distance) by the distance from these plants. Indeed, households choose simultaneously the amount and the marginal price for each characteristic, because the marginal price of each characteristic of the dwelling can vary with the amount of this characteristic. This simultaneous choice creates an identification problem in these regressions. ${ }^{21}$

The households' willingness to pay to move further away from highly hazardous plants decreases with respect to the distance from plants over the study area for Rouen (Table 8, Figure 5). This is due to the fact that the marginal gains (in terms of exposure reduction) of moving further away from the hazard source are likely to decrease. However, two other phenomena might explain the variations in the willingness to pay. First, other spatially correlated amenities could bias these estimated variations. Second, there might be sorting in the housing market, uncaptured by the buyer's observed characteristics: households with

\footnotetext{
${ }^{19}$ Results are similar when using the absolute willingness to pay.

${ }^{20}$ Indeed, the log-polynomial parametric model does not allow the marginal willingness to pay to vary with respect to time or the buyer's income. When explaining the marginal willingness to pay as estimated by the parametric regression also with respect to the time of sale and all of the buyer's characteristics, we find only a significant impact from time (a significant increase in 2002, 2004, and 2006).

${ }^{21}$ Ekeland (2004) offer two methods to implement this second-step regression by using data from a single market. However, our data do not enable us to apply them because the variability of the dwelling's characteristics with respect to the buyer's observed characteristics is required. This simultaneous choice also creates an endogeneity bias in the first step.
} 
Table 8: Explaining households' relative marginal willingness to pay to move one more meter away from highly hazardous plants in Rouen

\begin{tabular}{|c|c|c|c|c|c|c|}
\hline \multirow{2}{*}{$\begin{array}{l}\text { Explained variable } \\
\text { Explanatory variable }\end{array}$} & \multicolumn{3}{|c|}{$\begin{array}{c}\text { RMWTP estimated by } \\
\text { log-polynomial, OLS }\end{array}$} & \multicolumn{3}{|c|}{$\begin{array}{l}\text { RMWTP estimated } \\
\text { by log-linear, LWR }\end{array}$} \\
\hline & Estimate & Std. error & $p$-value & Estimate & Std. error & $p$-value \\
\hline Intercept & 2.6 & $5.7 \mathrm{e}-17$ & $<2 \mathrm{e}-16$ & 1.46 & 0.16 & $<2 \mathrm{e}-16$ \\
\hline Distance from plants & $-6.7 e-04$ & $3.2 \mathrm{e}-20$ & $<2 \mathrm{e}-16$ & $-2.4 \mathrm{e}-04$ & $1.8 \mathrm{e}-05$ & $<2 \mathrm{e}-16$ \\
\hline 2002 & & & & 0.089 & 0.054 & 0.10 \\
\hline 2004 & & & & 0.11 & 0.057 & 0.046 \\
\hline 2006 & & & & 0.26 & 0.060 & $3.1 \mathrm{e}-05$ \\
\hline 2008 & & & & 0.38 & 0.058 & $1.7 \mathrm{e}-10$ \\
\hline Income & & & & $-1.3 \mathrm{e}-07$ & $1.2 \mathrm{e}-06$ & 0.91 \\
\hline Age & & & & $1.0 \mathrm{e}-04$ & $2.2 \mathrm{e}-03$ & 0.96 \\
\hline Gender (men) & & & & 0.064 & 0.052 & 0.22 \\
\hline Farmer & & & & -0.043 & 0.31 & 0.89 \\
\hline Self-employed & & & & -0.092 & 0.11 & 0.39 \\
\hline Laborer & & & & -0.045 & 0.091 & 0.62 \\
\hline Manager or professional & & & & -0.060 & 0.094 & 0.52 \\
\hline Intermediate lower occupation & & & & -0.049 & 0.093 & 0.60 \\
\hline Intermediate upper occupation & & & & -0.062 & 0.086 & 0.47 \\
\hline Single & & & & -0.16 & 0.048 & $7.4 \mathrm{e}-4$ \\
\hline Coming from more than $15 \mathrm{~km}$ (France) & & & & -0.050 & 0.068 & 0.46 \\
\hline Coming from abroad & & & & -0.080 & 0.43 & 0.85 \\
\hline
\end{tabular}

Note: The buyer's characteristics are relative to the individual buyer or to the household reference person.

Sources: French solicitors - PERVAL, data collected and standardized by the Technical Studies Center of Public Works of Normandy and Centre, statements of income from the General Directorate of Public Finances. 571 observations.

a higher willingness to pay to live further away from the plants might intentionally choose a more distant location from these plants. We observe the net result of all three effects; it appears that the first effect dominates the last two. The decrease in the households' willingness to pay to move further away from plants is overestimated by the parametric model: the corresponding coefficient is three times higher (Table 8, Figure 5).

In the semiparametric model, the households' willingness to pay to move further away from highly hazardous plants increases over time following the 2001 AZF accident, this increase being significant at the $10 \%$ level (Table 8 ). Another analysis of the impact of the AZF accident on housing prices near a French facility similar to the AZF plant (Travers et al., 2009) (Port-Jérôme harbor, Seine-Maritime, France) shows the absence of an impact by using a parametric model. Here, the impact of the AZF accident might be more expected, because Grande Paroisse Normandy, which is settled in near Rouen, not only has a very similar activity to the AZF plant but also belongs to the same company, Grande Paroisse (a subsidiary of Total group). The willingness to pay also increases over time following the 2003 law (Table 8). This law implemented the technological disasters insurance system, which improves the coverage of households against technological disasters and might have 
Figure 5: Households' marginal willingness to pay to move one more meter away from highly hazardous plants for Rouen

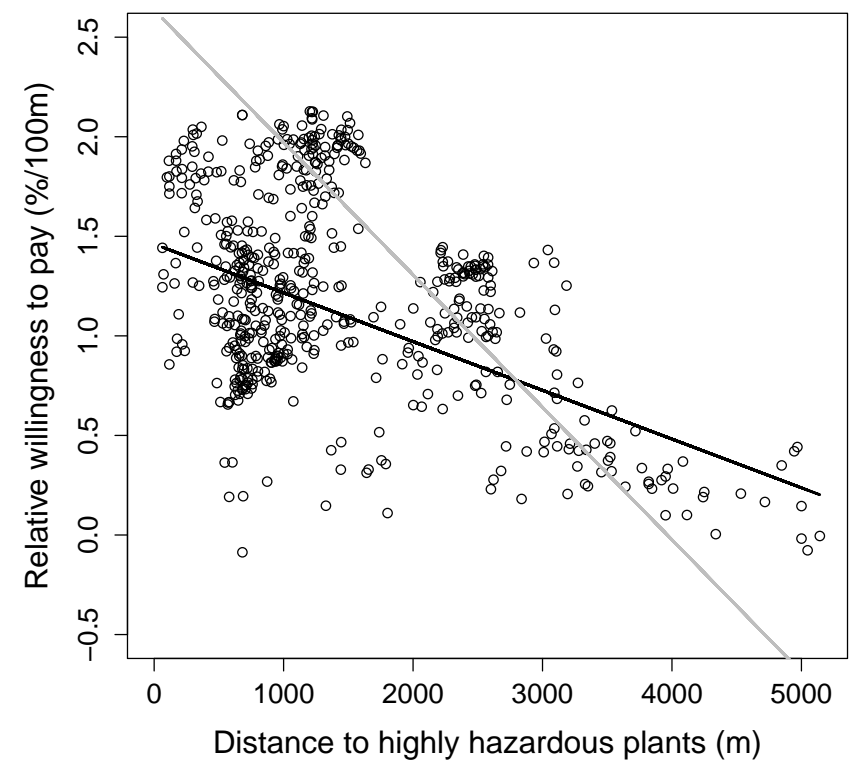

Caption: The relative marginal willingness to pay to move 100 more meters away from highly hazardous plants, as estimated from the semiparametric model, is a scatter plot. The slope as estimated by the semiparametric model is represented by a dark straight line. The slope estimated from the log-polynomial parametric model is represented by a grey straight line.

Sources: French solicitors - PERVAL, data collected and standardized by the Technical Studies Center of Public Works of Normandy and Centre, statements of income from the General Directorate of Public Finances. 571 observations. 
decreased their marginal willingness to pay. However, even if they were not straightaway effective, other measures of this law with a negative impact on homeowners (such as the implementation of technological risk prevention plans or mandatory information about risks) have probably got more media attention. The willingness to pay increases over time following the 2005 and 2007 information policies (Table 8). The buyer's characteristics of income, age, gender, and social and occupational groups do not significantly explain the willingness to pay to move further away from the plants (Table 8). ${ }^{22}$ Single people have a lower relative willingness to pay to move further away from highly hazardous plants, probably because they do not have any children. The buyers originating from more than $15 \mathrm{~km}$ from the study areas have a similar willingness to pay to move further away.

\section{Conclusion}

Real estate markets can reveal their households' willingness to pay to reduce their exposure to hazardous industrial facilities. Using very rich microdata, we study housing prices in the vicinity of hazardous industries located near three important French cities: Bordeaux, Dunkirk, and Rouen. We estimate the impact of the distance from hazardous plants on dwelling values by using hedonic price models.

We compare the results from standard parametric models of hedonic property and an alternative, more flexible, semiparametric model of hedonic property. This semiparametric model is a locally weighted regression that allows the willingness to pay to vary with respect to space, time of sale, and the buyers' characteristics while keeping some smoothness in its distribution. Even though the signs and orders of magnitude of the effects are similar in the two models for a very large majority of coefficients, the estimated impacts of the distance from highly hazardous plants on housing prices significantly differs between the two models. The parametric model leads to an important bias in the estimated value of this impact for Bordeaux and Rouen and in its variations with respect to the distance from the plants for Rouen.

Using the semiparametric model, we show that this impact strongly differs among industrial areas, even among chemical and petrochemical industries, likely because of the different perceptions of industrial risks and dissimilar neighborhoods of these hazardous facilities.

\footnotetext{
${ }^{22}$ This absence of a significant impact holds when considering other specifications (with polynomials or $\log )$.
} 
We also show that this impact can vary within a study area. Indeed, the impact of the distance from hazardous plants on housing prices can significantly decrease with respect to the distance from the plants because the marginal gains in terms of the exposure reduction of moving further away from the hazard source are likely to decrease; it can also vary over time following accidents, information policies, or risk management laws.

There are two substantive lessons from our analysis. First, our results show that parametric models can lead to an important bias in the estimated value of the marginal willingness to pay. Second, our results show that the estimated willingness to pay for prevention strongly differs among industrial areas, even among one category of industries, and depends on the distance from these facilities and on time. This inadequate estimation method and this limited external validity call for careful use of the current estimations of the population's willingness to pay for industrial risk reduction in the cost-benefit analyses of prevention measures. Until now, most cost-benefit analyses have used the parameters taken from the estimation of parametric hedonic models on other study areas and time frames than the ones under consideration in these analyses.

\section{References}

Anglin, P.M., Gencay, R., 1996. Semiparametric Estimation of a Hedonic Price Function. Journal of Applied Econometrics 11, 633-648.

Bin, O., Kruse, J.B., Landry, C.E., 2008. Flood Hazards, Insurance Rates, and Amenities: Evidence From the Coastal Housing Market. Journal of Risk and Insurance 75, 63-82.

Bontemps, C., Simioni, M., Surry, Y., 2008. Semiparametric Hedonic Price Models: Assessing the Effects of Agricultural Nonpoint Source Pollution. Journal of Applied Econometrics $23,825-842$.

Boxall, P.C., Chan, W.H., McMillan, M.L., 2005. The Impact of Oil and Natural Gas Facilities on Rural Residential Property Values: A Spatial Hedonic Analysis. Resource and Energy Economics 27, 248-269.

Carroll, T.M., Clauretie, T.M., Jensen, J., Waddoups, M., 1996. The Economic Impact of a Transient Hazard on Property Values: The 1988 PEPCON Explosion in Henderson, Nevada. Journal of Real Estate Finance and Economics 13, 143-167.

Chay, K.Y., Greenstone, M., 2005. Does Air Quality Matter? Evidence From the Housing Market. Journal of Political Economy 113, 376-424.

Clark, D.E., Nieves, L.A., 1994. An Interregional Hedonic Analysis of Noxious Facility Impacts on Local Wages and Property Values. Journal of Environmental Economics and Management 27, 235-253. 
Currie, J., Davis, L.W., Greenstone, M., Walker, R., 2013. Do Housing Prices Reflect Environmental Health Risks? Evidence from More than 1600 Toxic Plant Openings and Closings. National Bureau of Economic Research.

Davis, L.W., 2011. The Effect of Power Plants on Local Housing Values and Rents. Review of Economics and Statistics 93, 1391-1402.

Ekeland, I., Heckman, J.J., Nesheim, L., 2004. Identification and Estimation of Hedonic Models. Journal of Political Economy 112, 60-109.

Farber, S., 1998. SURVEY Undesirable Facilities and Property Values: A Summary of Empirical Studies. Ecological Economics 24, 1-14.

Flower, P.C., Ragas, W.R., 1994. The Effects of Refineries on Neighborhood Property Values. Journal of Real Estate Research 9, 319-338.

Freeman, A.M., 2003. Property Value Models, in The Measurement of Environmental and Resource Values: Theory and Methods. Resource for the Future.

Gayer, T., Hamilton, J.T., Viscusi, W.K., 2000. Private Values of Risk Tradeoffs at Superfund Sites : Housing Market Evidence on Learning about Risk. Review of Economics and Statistics 82, 439-451.

Greenstone, M., Gallagher, J., 2008. Does Hazardous Waste Matter? Evidence From the Housing Market and the Superfund Program. Quarterly Journal of Economics 123, 9511003.

Greenstone, M., Hornbeck, R., Moretti, E., 2010. Identifying Agglomeration Spillovers: Evidence from Winners and Losers of Large Plant Openings. Journal of Political Economy 118, 536-598.

Grislain-Letrémy, C., Katossky, A., 2013. L'Impact de l'Industrie à Hauts Risques sur le Prix des Logements. Economie et Statistique 460-461, 79-106.

Harrison, D.M., Smersh, G.T., Schwartz, A.L.Jr., 2001. Environmental Determinants of Housing Prices : The Impact of Flood Zone Status. Journal of Real Estate Research 21, $3-20$.

Kohlhase, J.E., 1991. The Impact of Toxic Waste Sites on Housing Values. Journal of Urban Economics 30, 1-26.

MacDonald, D.N., White, H.L., Taube, P.M., Huth, W.L., 1990. Flood Hazard Pricing and Insurance Premium Differentials: Evidence from the Housing Market. Journal of Risk and Insurance 57, 654-663.

Maslianskaïa-Pautrel, M., 2008. La Valorisation de la Qualité de l'Air Par l'Approche Hédonique : Une Revue de la Littérature.

McMillen, D.P., 2010. Issues in Spatial Data Analysis. Journal of Regional Science 50, 119-141.

McMillen, D.P., Redfearn, C.L., 2010. Estimation and Hypothesis Testing for Nonparametric Hedonic House Price Functions. Journal of Regional Science 50, 712-733.

Morgan, A., 2007. The Impact of Hurricane Ivan on Expected Flood Losses, Perceived Flood Risk, and Property Values. Journal of Housing Research 16, 47-60.

Pope, J., 2008. Buyer Information and the Hedonic: The Impact of a Seller Disclosure on the Implicit Price for Airport Noise. Journal of Urban Economics 63, 498-516. 
Redfearn, C.L., 2009. How Informative are Average Effects? Hedonic Regression and Amenity Capitalization in Complex Urban Housing Markets. Regional Science and Urban Economics 39, 297-306.

Rosen, S., 1974. Hedonic Prices and Implicit Markets: Product Differentiation in Pure Competition. Journal of Political Economy 82, 34-55.

Sauvage, L., 1997. L'Impact du Risque Industriel sur l'Immobilier. Association des Etudes Foncières, Association Des Études Foncières.

Sunding, D.L., Swoboda, A.M., 2010. Hedonic Analysis with Locally Weighted Regression: An Application to the Shadow Cost of Housing Regulation in Southern California. Regional Science and Urban Economics 40, 550-573.

Travers, M., Bonnet, E., Chevé, M., Appéré, G., 2009. Risques Industriels et Zone Naturelle Estuarienne : Une Analyse Hédoniste Spatiale. Economie et Prévision 4-5, 136-158.

\section{A Appendices}

\section{A.1 Descriptive statistics}


Table 9: Intrinsic characteristics of the dwellings

\begin{tabular}{|c|c|c|c|c|}
\hline & & Bordeaux & Dunkirk & Rouen \\
\hline $\mathrm{N}$ & & 1423 & 1016 & 571 \\
\hline \multirow{7}{*}{ Price (current euro, tax. inc.) } & Min & 22090 & 7622 & 15245 \\
\hline & Q1 & 146428 & 76222 & 92994 \\
\hline & Median & 197000 & 99092 & 115850 \\
\hline & Q3 & 256305 & 128000 & 154000 \\
\hline & Max & 800000 & 285300 & 430000 \\
\hline & Mean & 206887 & 104860 & 126402 \\
\hline & Standard deviation & 85661 & 41021 & 54707 \\
\hline Less than 5 years old & & 83 & 6 & 15 \\
\hline \multirow[t]{3}{*}{ Condition } & Good & 497 & 525 & 179 \\
\hline & Average & 857 & 297 & 339 \\
\hline & Poor & 69 & 194 & 53 \\
\hline \multirow[t]{8}{*}{ Living space $(\mathrm{sq} \mathrm{m})(*)$} & Min & 30 & 46 & 30 \\
\hline & Q1 & 95 & 85 & 83 \\
\hline & Median & 110 & 95 & 100 \\
\hline & Q3 & 134 & 110 & 120 \\
\hline & $\operatorname{Max}$ & 350 & 300 & 300 \\
\hline & Mean & 119 & 100 & 104 \\
\hline & Standard deviation & 36 & 25 & 34 \\
\hline & Unspecified & 260 & 210 & 268 \\
\hline \multirow[t]{5}{*}{ Number of rooms } & 3 or less $(\dagger)$ & 109 & 77 & 71 \\
\hline & 4 & 361 & 268 & 131 \\
\hline & 5 & 506 & 441 & 177 \\
\hline & 6 & 288 & 161 & 115 \\
\hline & 7 or more & 159 & 69 & 77 \\
\hline \multirow[t]{3}{*}{ Number of bathrooms } & 0 & 34 & 80 & 0 \\
\hline & 1 & 917 & 881 & 450 \\
\hline & 2 or more & 472 & 55 & 121 \\
\hline \multirow[t]{3}{*}{ Number of parking spaces } & 0 & 304 & 1016 & 127 \\
\hline & 1 & 971 & 0 & 299 \\
\hline & 2 or more & 148 & 0 & 145 \\
\hline \multirow[t]{6}{*}{ Holds... } & $\ldots$ a terrace & 83 & 9 & 56 \\
\hline & ... a swimming pool & 207 & 0 & 0 \\
\hline & ... a basement & 72 & 345 & 266 \\
\hline & ... a cellar & 83 & 47 & 255 \\
\hline & ... outbuildings & 161 & 154 & 118 \\
\hline & $\ldots$ an attic & 70 & 65 & 202 \\
\hline \multirow[t]{7}{*}{ Total acreage (sq $\mathrm{m})$} & Min & 30 & 0 & 30 \\
\hline & Q1 & 606 & 155 & 316 \\
\hline & Median & 816 & 207 & 500 \\
\hline & Q3 & 1052 & 305 & 848 \\
\hline & $\operatorname{Max}$ & 29597 & 6599 & 18724 \\
\hline & Mean & 967 & 266 & 783 \\
\hline & Standard deviation & 1115 & 261 & 1355 \\
\hline
\end{tabular}

Notes: The unit is the number of dwellings, unless specified otherwise.

(*) Living space is filled in for $81 \%$ of the observations for Bordeaux, $80 \%$ for Dunkirk, and $62 \%$ for Rouen. The imputed living space for missing values is randomly chosen among the observed distribution of living spaces.

$(\dagger)$ Observations with zero room (stand-alone garages, garden sheds, or other outbuildings) are excluded.

Sources: French solicitors - PERVAL, data collected and standardized by the Technical Studies Center of Public Works of Normandy and Centre, Nord and Picardy, and South West France. 
Table 10: Extrinsic characteristics of the dwellings

\begin{tabular}{|c|c|c|c|c|}
\hline & & Bordeaux & Dunkirk & Rouen \\
\hline $\mathrm{N}$ & & 1423 & 1016 & 571 \\
\hline \multirow{7}{*}{$\begin{array}{l}\text { Commuting time } \\
\text { (by car) from city } \\
\text { center (min) }\end{array}$} & Min & 16 & 6 & 16 \\
\hline & Q1 & 24 & 8 & 19 \\
\hline & Median & 28 & 9 & 22 \\
\hline & Q3 & 31 & 10 & 25 \\
\hline & $\operatorname{Max}$ & 38 & 14 & 31 \\
\hline & Mean & 27 & 9 & 22 \\
\hline & Standard deviation & 4 & 2 & 4 \\
\hline \multirow[t]{7}{*}{ Located close to... } & $\ldots$ the market square $(<500 \mathrm{~m})$ & 205 & 295 & 97 \\
\hline & $\ldots$ a drugstore $(<250 \mathrm{~m})$ & 144 & 460 & 109 \\
\hline & $\ldots$ a food shop $(<250 \mathrm{~m})$ & 198 & 686 & 214 \\
\hline & $\ldots$ a bus stop $(<250 \mathrm{~m})$ & 676 & 880 & 448 \\
\hline & $\ldots$ a park $(<500 \mathrm{~m})$ & 425 & 714 & 119 \\
\hline & $\ldots$ a nursery or a primary school $(<500 \mathrm{~m})$ & 428 & 924 & 172 \\
\hline & $\ldots$ a high school $(<500 \mathrm{~m})$ & 158 & 541 & 161 \\
\hline \multirow{7}{*}{$\begin{array}{l}\text { Distance from the } \\
\text { nearest highly } \\
\text { hazardous plant } \\
\text { (m) }\end{array}$} & Min & 532 & 41 & 64 \\
\hline & Q1 & 3333 & 837 & 705 \\
\hline & Median & 5141 & 1730 & 1140 \\
\hline & Q3 & 6406 & 2451 & 2189 \\
\hline & Max & 10379 & 4084 & 5142 \\
\hline & Mean & 4935 & 1711 & 1452 \\
\hline & Standard deviation & 1863 & 949 & 1027 \\
\hline \multirow{7}{*}{$\begin{array}{l}\text { Distance from the } \\
\text { nearest } \\
\text { authorized plant } \\
(\mathrm{m})\end{array}$} & Min & 89 & 41 & 64 \\
\hline & Q1 & 1006 & 596 & 494 \\
\hline & Median & 1657 & 872 & 771 \\
\hline & Q3 & 2663 & 1163 & 1189 \\
\hline & Max & 5279 & 1943 & 2884 \\
\hline & Mean & 1848 & 877 & 943 \\
\hline & Standard deviation & 1061 & 369 & 624 \\
\hline View of industrial plants & & 0 & 0 & 495 \\
\hline \multirow{7}{*}{$\begin{array}{l}\text { Located in an } \\
\text { administrative } \\
\text { area of... }\end{array}$} & ... land use control (Z1) & 0 & 0 & 34 \\
\hline & ... land use control (Z2) & 0 & 0 & 56 \\
\hline & ... emergency plan & 0 & 276 & 391 \\
\hline & ... natural hazard & 33 & 0 & 0 \\
\hline & ... other hazard & 0 & 0 & 58 \\
\hline & ... environmental protection & 0 & 0 & 61 \\
\hline & ... conservation easement & 0 & 39 & 200 \\
\hline \multirow[t]{2}{*}{ Exposed to... } & $\ldots$ land transport noise $(\star)$ & 0 & 0 & 15 \\
\hline & $\ldots$ air transport noise $(\star)$ & 79 & 0 & 0 \\
\hline
\end{tabular}

Notes: The unit is the number of dwellings, unless specified otherwise.

$(\star)$ A dwelling is considered as exposed to a land transport facility if the sound is above $60 \mathrm{~dB}$ and to an air transport facility if the sound is above $50 \mathrm{~dB}$.

Sources: French solicitors - PERVAL, data collected and standardized by the Technical Studies Center of Public Works of Normandy and Centre, Nord and Picardy, and South West France. 
Table 11: Buyers' characteristics

\begin{tabular}{|c|c|c|c|c|}
\hline & & Bordeaux & Dunkirk & Rouen \\
\hline $\mathrm{N}$ & & 1423 & 1016 & 571 \\
\hline \multirow[t]{8}{*}{ Income (euro) } & Min & 5024 & 3471 & 7550 \\
\hline & Q1 & 20498 & 12134 & 13563 \\
\hline & Median & 38815 & 23266 & 28958 \\
\hline & Q3 & 47942 & 32544 & 35408 \\
\hline & Max & 173016 & 160996 & 277797 \\
\hline & Mean & 35609 & 23781 & 27161 \\
\hline & Standard deviation & 16061 & 12348 & 17777 \\
\hline & Unspecified & 112 & 64 & 114 \\
\hline \multirow[t]{2}{*}{ Gender } & Female & 229 & 200 & 99 \\
\hline & Male & 1194 & 816 & 472 \\
\hline \multirow[t]{8}{*}{ Age (year) } & Min & 20 & 20 & 22 \\
\hline & Q1 & 34 & 29 & 31 \\
\hline & Median & 40 & 34 & 37 \\
\hline & Q3 & 48 & 43 & 46 \\
\hline & Max & 99 & 82 & 85 \\
\hline & Mean & 42 & 37 & 40 \\
\hline & Standard deviation & 11 & 11 & 11 \\
\hline & Unspecified & 0 & 0 & 1 \\
\hline \multirow{9}{*}{$\begin{array}{l}\text { Social and } \\
\text { occupational } \\
\text { group }\end{array}$} & Farmer & 3 & 1 & 2 \\
\hline & Self-employed & 71 & 31 & 31 \\
\hline & Managerial or professional occupation & 445 & 47 & 77 \\
\hline & Intermediate upper occupation & 472 & 203 & 188 \\
\hline & Employee & 193 & 112 & 91 \\
\hline & Worker & 103 & 180 & 131 \\
\hline & Retired & 100 & 28 & 41 \\
\hline & No occupation & 22 & 13 & 7 \\
\hline & Unspecified & 14 & 401 & 3 \\
\hline \multirow[t]{5}{*}{ Marital status } & Single & 301 & 322 & 172 \\
\hline & In civil union & 16 & 17 & 7 \\
\hline & Married & 884 & 538 & 309 \\
\hline & Divorced & 158 & 101 & 50 \\
\hline & Widowed & 34 & 18 & 18 \\
\hline \multirow[t]{5}{*}{ Originates from... } & ... the study area & 633 & 758 & 199 \\
\hline & ... less than $15 \mathrm{~km}$ from the study area & 358 & 155 & 324 \\
\hline & ... more than $15 \mathrm{~km}$ (France) & 391 & 95 & 47 \\
\hline & ... abroad & 11 & 6 & 1 \\
\hline & Unspecified & 30 & 2 & 0 \\
\hline
\end{tabular}

Notes: The buyer's characteristics are relative to the individual buyer or to the household reference person. The unit is the number of buyers, unless specified otherwise.

Sources: French solicitors - PERVAL, data collected and standardized by the Technical Studies Center of Public Works of Normandy and Centre, Nord and Picardy, and South West France, and statements of income from the General Directorate of Public Finances. 
Table 12: Transactions by municipality and by year

\begin{tabular}{llrrrrrr}
\hline Area & Municipality (INSEE code) & 2000 & 2002 & 2004 & 2006 & 2008 & All years \\
\hline Bordeaux & Le Haillan (33200) & 36 & 31 & 34 & 38 & 24 & 163 \\
& Martignas-Sur-Jalle (33273) & 42 & 40 & 42 & 32 & 30 & 186 \\
& Mérignac (33281) & 13 & 15 & 22 & 13 & 11 & 74 \\
& Saint-Aubin-de-Médoc (33376) & 34 & 38 & 38 & 28 & 21 & 159 \\
& Saint-Médard-en-Jalles (33449) & 48 & 157 & 155 & 149 & 84 & 593 \\
& Le Taillan-Médoc (33519) & 52 & 50 & 55 & 49 & 42 & 248 \\
\cline { 2 - 7 } & All municipalities & 225 & 331 & 346 & 309 & 212 & 1423 \\
\hline Dunkirk & Coudekerque-Branche (59155) & 80 & 77 & 87 & 86 & 85 & 415 \\
& Dunkirk (59183) & 47 & 35 & 49 & 39 & 41 & 211 \\
& Fort-Mardyck (59248) & 9 & 12 & 8 & 17 & 16 & 62 \\
& Saint-Pol-sur-Mer (59540) & 50 & 67 & 86 & 56 & 69 & 328 \\
\cline { 2 - 7 } & All municipalities & 186 & 191 & 230 & 198 & 211 & 1016 \\
\hline Rouen & Grand-Couronne (76319) & 48 & 58 & 57 & 42 & 50 & 255 \\
& Moulineaux (76457) & 6 & 10 & 4 & 7 & 5 & 32 \\
& Petit-Couronne (76497) & 43 & 45 & 29 & 28 & 38 & 183 \\
& Sahurs (76550) & 10 & 15 & 9 & 9 & 5 & 48 \\
& Val-de-la-Haye (76717) & 7 & 7 & 13 & 8 & 6 & 41 \\
\cline { 2 - 7 } & All municipalities & 118 & 140 & 113 & 94 & 106 & 571 \\
\hline All areas & & 529 & 662 & 689 & 601 & 529 & 3010 \\
\hline Note: The
\end{tabular}

Note: The unit is the number of transactions.

Sources: French solicitors - PERVAL, data collected and standardized by the Technical Studies Center of Public Works of Normandy and Centre, Nord and Picardy, and South West France.

\section{A.2 Other studies on the impact of hazardous chemical and petrochem- ical industries on housing prices}


